\title{
Altered Clock and Lipid Metabolism-Related Genes in Atherosclerotic Mice Kept with Abnormal Lighting Condition
}

\author{
Zhu Zhu, ${ }^{1}$ Bingxuan Hua, ${ }^{2}$ Zhanxian Shang, ${ }^{1}$ Gongsheng Yuan, ${ }^{1}$ Lirong Xu, ${ }^{1}$ Ermin Li, \\ Xiaobo Li, ${ }^{1}$ Ning Sun, ${ }^{1}$ Zuoqin Yan, ${ }^{2}$ Ruizhe Qian, ${ }^{1}$ and Chao Lu ${ }^{1}$ \\ ${ }^{1}$ Department of Physiology and Pathophysiology, School of Basic Medical Sciences, Fudan University, Shanghai 200032, China \\ ${ }^{2}$ Department of Orthopedics, Zhongshan Hospital, Fudan University, Shanghai 200032, China
}

Correspondence should be addressed to Chao Lu; luchao@shmu.edu.cn

Received 8 March 2016; Revised 11 May 2016; Accepted 25 July 2016

Academic Editor: Henrik Oster

Copyright (C) 2016 Zhu Zhu et al. This is an open access article distributed under the Creative Commons Attribution License, which permits unrestricted use, distribution, and reproduction in any medium, provided the original work is properly cited.

\begin{abstract}
Background. The risk of atherosclerosis is elevated in abnormal lipid metabolism and circadian rhythm disorder. We investigated whether abnormal lighting condition would have influenced the circadian expression of clock genes and clock-controlled lipid metabolism-related genes in ApoE-KO mice. Methods. A mouse model of atherosclerosis with circadian clock genes expression disorder was established using ApoE-KO mice (ApoE-KO LD/DL mice) by altering exposure to light. C57 BL/6J mice (C57 mice) and ApoE-KO mice (ApoE-KO mice) exposed to normal day and night and normal diet served as control mice. According to zeitgeber time samples were acquired, to test atheromatous plaque formation, serum lipids levels and rhythmicity, clock genes, and lipid metabolism-related genes along with Sirtuin 1 (Sirt1) levels and rhythmicity. Results. Atherosclerosis plaques were formed in the aortic arch of ApoE-KO LD/DL mice. The serum lipids levels and oscillations in ApoE-KO LD/DL mice were altered, along with the levels and diurnal oscillations of circadian genes, lipid metabolism-associated genes, and Sirtl compared with the control mice. Conclusions. Abnormal exposure to light aggravated plaque formation and exacerbated disorders of serum lipids and clock genes, lipid metabolism genes and Sirt1 levels, and circadian oscillation.
\end{abstract}

\section{Introduction}

All species on the earth exhibit circadian rhythms synchronized with the environmental cycles of day and night. In mammals, the circadian pattern consists of a central clock located in the suprachiasmatic nucleus (SCN) and a peripheral clock spread over almost all of the major organ systems including liver and fat $[1,2]$. The SCN senses the external light signal and releases neurotransmitters and hormones in response, which regularly influence the circadian expression of the clock genes in the peripheral tissues [3]. These peripheral oscillators play a critical tissue-specific role [4]. The circadian rhythm of animals is manifested via feedback loop formed by a number of clock genes. The main mammalian circadian clock genes include circadian locomotor output cycles kaput (Clock), brain and muscle encoding Arntlike protein 1 (Bmal1), nuclear receptor subfamily 1 , group D, member 1 (Rev-erb $\alpha$ ), period (Per1, Per2, Per3), and cryptochrome (Cry1, Cry2). Many physiological activities are synchronized in an orderly manner by regulating the clock genes and their controlled genes. Hundreds of metabolismrelated genes show circadian rhythms and most of them are controlled directly or indirectly by clock genes [5]. The peroxisome proliferator-activated receptors (PPARs), RARrelated orphan receptor $\alpha(R O R \alpha)$, and retinoid $\mathrm{X}$ receptor $\alpha(R X R \alpha)$ are associated with lipid metabolism and exhibit circadian oscillations [6-9].

Currently, atherosclerotic cardiovascular disease (ASCVD) is a major health threat [10] and the primary contributor to death worldwide. The increasing burden of atherosclerotic cardiovascular risk is attributed to the escalating incidence of obesity, hypercholesterolemia, and dyslipidemia [11]. Cholesterol is a key component of arterial plaques [12] and liver is the major seat of cholesterol metabolism. Further, abdominal visceral fat has been strongly associated with cardiovascular risk $[13,14]$. 
Studies demonstrate that ASCVD has a close relationship with circadian clocks. Disordered circadian rhythms induce vascular impairment and aggravate atherosclerosis [15]. Humans and mice with dysfunctional circadian oscillation are more likely to manifest cardiovascular diseases, while rats with hypertension also have irregular circadian gene expression [15-17]. Shift work accelerates atherosclerosis, which is a major manifestation of the pathophysiology underlying cardiovascular disease [18]. The deleterious effects of shift work on subclinical atherosclerosis are apparent in men before the age of 40 [19].

Sirtuin 1 (Sirt1) a nuclear protein targeting histone $\mathrm{H} 3$ and H4 deacetylation [20] and its enzymatic activity also exhibit a circadian change [21]. Further, Sirt1 plays a significant protective role in atherosclerosis [22]. Sirt1 especially regulates hepatic lipid metabolism by inhibiting fat synthesis and promoting fat oxidation [23-25]. It increases fat mobilization in white fat tissue by inhibiting PPAR $\gamma$ [26].

The circadian clock disorder of atherosclerotic mice has been found in mouse SCN, heart, and liver [27]. It is unclear whether peripheral clocks, lipid metabolism-related genes, and atheroprotective factor Sirt1 are altered in the liver and fat of atherosclerotic mice. We generated a mouse model of atherosclerotic via abnormal alteration in day and night and tested for atherosclerotic plaque formation and circadian expression in clock genes. We also examined the diurnal expression of clock genes Bmal1, Per2, and Cry1 Rev-erb $\alpha$, as well as lipid metabolism-related PPAR $\alpha, P P A R \gamma, R O R \alpha$, $R X R \alpha$, and Sirt1.

\section{Materials and Methods}

2.1. Animal Model. We selected 10-week-old male C57BL/6J mice (Laboratory Animal Research Center of Chinese Academy of Sciences, Shanghai, China) and the age and gender were matched to ApoE-KO mice (Beijing Laboratory Animal Research Center, Beijing, China). ApoE-KO mouse is an ideal model of atherosclerosis [28, 29]. And the abnormal light stimulation leads to circadian disorder [30]. Therefore, the atherosclerosis model manifesting circadian clock genes expression disorder was built by altering exposure to environmental light. The ApoE-KO mice were randomly divided into two groups: (1) mice (ApoE-KO group) exposed to normal day-night pattern and (2) mice (ApoE-KO LD/DL group) maintained on a light-dark (LD) cycle ( $12 \mathrm{~h}$ light/12 h dark) for 2 weeks, followed by a dark-light (DL) cycle for 2 weeks, and then transferred to another LD cycle for 2 weeks. All mice were free to obtain regular diet and water. All the samples were obtained from mice at the end of the six weeks. According to external cues called zeitgeber times (ZT stands for standardized notation for the time during an entrained circadian cycle, ZT0 represents the start of the light phase, and ZT12 is the beginning of the dark phase, during a 24-hour light-dark cycle), we controlled light on at 08:00 which was designated as zeitgeber time 0 (ZT0) and light off at 20:00 (ZT12). The liver and fat tissues were obtained at different time points including ZT0, ZT4, ZT8, ZT12, ZT16, and ZT20 (four mice per time point). The samples were immediately frozen in liquid nitrogen and stored at $-80^{\circ} \mathrm{C}$. All the animal experiments were performed according to the criteria of the Medical Laboratory Animal Administrative Committee of Shanghai. This study was approved by the Medical Ethics Committee of Fudan University, Shanghai, China.

2.2. Analysis of Mouse Serum Lipids. The serum was used for lipid detection. The mice were generally anesthetized by administering chloral hydrate at ZT0, ZT4, ZT8, ZT12, ZT16, and ZT20. Blood was immediately collected after removing the whole eye ball. Subsequently, mice were euthanized with pentobarbital sodium through intraperitoneal injection. The serum was collected by centrifugation for $30 \mathrm{~min}$ at $4^{\circ} \mathrm{C}$ followed by serum lipid detection. The levels of glucose, triglyceride, total cholesterol, and low-density lipoprotein (LDL) in serum were measured by enzymatic methods [14]. The kits were purchased from Rongsheng Biotechnology Company Ltd. (Shanghai, China). We tested the samples according to the manufacturer's instruction.

2.3. Tissue Staining. To investigate the effect of abnormal light stimulation on atheromatous plaque formation in mice, we used Oil Red O staining to determine vulnerable plaque formation as previously described [30]. The arterial arcades were carefully dissected and fixed in $4 \%$ paraformaldehyde for $24 \mathrm{~h}$ at room temperature. The fixed samples were rinsed three times, each time for 15 minutes. The aortic segments were dehydrated in $20 \%$ sugar solution for $24 \mathrm{~h}$ and $30 \%$ sucrose solution for $24 \mathrm{~h}$. Subsequently, the samples were embedded in Tissue-Tek OCT compound. Serial sections of $10 \mu \mathrm{m}$ crosssection were prepared and fixed at $4^{\circ} \mathrm{C}$ using $70 \%$ ethanol solution and staining for $1 \mathrm{~min}$ in Oil Red O (Sigma-Aldrich, O0625, USA) to identify atherosclerotic plaques. Oil Red O was dissolved in isopropanol and mixed in $3: 2(\mathrm{v} / \mathrm{v})$ (water to Oil Red O) and the plaques were stained for $30 \mathrm{~min}$. Then the samples were carefully washed for three times, each time for 5 minutes and stained for 3 5 min in hematoxylin (Beyotime, C0107, China).

2.4. Total RNA Extraction and Reverse Transcription. Total RNA from liver and fat were isolated with TRIzol reagent (Invitrogen Life Technologies), according to the manufacturer's instructions. The quantity of total RNA was determined using UV spectrophotometry. RNA integrity was assessed using agarose gel electrophoresis, followed by reverse transcription of $1 \mu \mathrm{g}$ of total RNA. The amplified firststrand cDNA was prepared with oligo-dT primers using a commercial cDNA synthesis kit (ReverTra Ace qPCR RT kit, Toyobo, Osaka, Japan). The cDNA was subsequently amplified for 35 cycles using specific primers (Table 1).

2.5. Real-Time PCR. The cDNA was diluted to $10 \mathrm{ng} / \mu \mathrm{L}$ and PCR reactions were amplified on a real-time PCR machine (Bio-Rad, Hercules, CA, USA). The PCR reaction mixture included $2.5 \mu \mathrm{L}$ of $10 \mathrm{ng} / \mu \mathrm{L}$ cDNA, $1 \mu \mathrm{L}$ of $10 \mu \mathrm{M}$ primers ( $0.5 \mu \mathrm{L}$ of upstream primers, $0.5 \mu \mathrm{L}$ of downstream primers), $10 \mu \mathrm{L}$ SYBR Green real-time PCR Master mix (Bio-Rad, Hercules, CA, USA), and $7.5 \mu \mathrm{L}$ of $\mathrm{H}_{2} \mathrm{O}$, in a final volume of $20 \mu \mathrm{L}$. The samples were subjected to 35 cycles of amplification. The amplification protocol included denaturation at $94^{\circ} \mathrm{C}$ for 
TABLE 1: Primer pairs used to amplify PCR products.

\begin{tabular}{|c|c|c|c|}
\hline Gene name & $\begin{array}{l}\text { Annealing } \\
\text { temperature }\end{array}$ & $\begin{array}{c}\text { GeneBank } \\
\text { accession } \\
\text { number }\end{array}$ & Forward primer $\left(5^{\prime}-3^{\prime}\right)$ \\
\hline Bmall & $60^{\circ} \mathrm{C}$ & NM_007489 & $\begin{array}{c}\text { Forward: CACTGACTACCAAGAAAGTATG } \\
\text { Reverse: ATCCATCTGCTGCCCTGAGA }\end{array}$ \\
\hline Per2 & $58^{\circ} \mathrm{C}$ & NM_011066 & $\begin{array}{l}\text { Forward: CAGACTCATGATGACAGAGG } \\
\text { Reverse: GAGATGTACAGGATCTTCCC }\end{array}$ \\
\hline Rev-erb $\alpha$ & $60^{\circ} \mathrm{C}$ & NM_145434 & $\begin{array}{l}\text { Forward: TACATTGGCTCTAGTGGCTCC } \\
\text { Reverse: CAGTAGGTGATGGTGGGAAGTA }\end{array}$ \\
\hline Cryl & $58^{\circ} \mathrm{C}$ & NM_007771 & $\begin{array}{l}\text { Forward: CACTGGTTCCGAAAGGGACTC } \\
\text { Reverse: CTGAAGCAAAAATCGCCACCT }\end{array}$ \\
\hline $\operatorname{PPAR} \alpha$ & $61^{\circ} \mathrm{C}$ & NM_011144 & $\begin{array}{l}\text { Forward: TCGGCGAACTATTCGGCTG } \\
\text { Reverse: GCACTTGTGAAAACGGCAGT }\end{array}$ \\
\hline $\operatorname{ROR} \alpha$ & $61^{\circ} \mathrm{C}$ & NM_013646 & $\begin{array}{l}\text { Forward: GGGGACAATTTCTACTTCACTGG } \\
\text { Reverse: GCAAACGGTAGTAAGGGCTG }\end{array}$ \\
\hline GAPDH & $60^{\circ} \mathrm{C}$ & BC_083149 & $\begin{array}{l}\text { Forward: ACAGCCGCATCTTCTTGTGCAGT } \\
\text { Reverse: GGCCTTGACTGTGCCGTGAATTT }\end{array}$ \\
\hline
\end{tabular}

$15 \mathrm{sec}$, primer annealing for $30 \mathrm{sec}$, and extension at $72^{\circ} \mathrm{C}$ for $30 \mathrm{sec}$. Melting profiles were performed following each PCR reaction. The relative quantification of gene expression was analyzed from the measured threshold cycles (CT) using the $2^{-\Delta \Delta \mathrm{CT}}$ method. The CT value represents the number of cycles at the cross-point of $\Delta \mathrm{Rn}$ versus threshold. The higher the CT value, the greater the number of steady cycles and the lower the gene expression. As the amplification efficiencies of the target genes and the internal control were equal, the relative changes in the target gene expression of the altered clock genes in the mice compared with normal mice $(\Delta \mathrm{CT}$ calibrator value) were calculated using the equation $2^{-\Delta \Delta C T}$. The $\Delta \mathrm{CT}$ values were determined by subtracting the average GAPDH CT value from the average target gene CT value.

2.6. Statistical Analysis. Each value represents mean \pm SD. The values for mRNA levels are presented as relative values in all experiments. We employed single cosinor method to analyze circadian rhythm $[17,31]$, and the equation used for stating cosine function was shown as follows: $Y(t)=M+$ $A * \cos (x * t+u)$. The mesors, amplitudes, and acrophases were rhythm characteristics and estimated by this method. The mesor represents middle value of the fitted cosine. The amplitude is from half of the biggest differences (Value max $_{\text {- }}$ Value $_{\text {min }}$ ) in the fitted cosine function. And the acrophase means the peak value time. A probability value determined by one-way analysis of variance (ANOVA) of $\leq 0.05$ indicated a statistically significant difference. Primer sequences of the target genes in the present study were found in GeneBank as shown in Table 1.

\section{Results}

3.1. Atheromatous Plaque Formation in the Arterial Arch. To investigate the effect of abnormal light stimulation on atheromatous plaque formation in mice, Oil Red $\mathrm{O}$ staining was used to determine vulnerable plaque formation. 10-weekold ApoE-KO mice were divided into two groups randomly.
The wild type C57 BL/6J (C57) mice and one group of ApoE knockout (ApoE-KO) mice were exposed to regular lightdark conditions. The other group of ApoE-KO mice (ApoE$\mathrm{KO}$ LD/DL) was exposed to abnormal light stimulation. Thus, three experimental groups were created. The arterial arch of C57 mice, ApoE-KO mice, and ApoE-KO LD/DL mice was dyed with Oil Red O (Figure 1). No pathological change was observed in C57 mice (Figure 1(a)). Compared with C57 mice, the ApoE-KO mice showed endothelial lipid deposition and foam cell formation (Figure 1(b)). In ApoE-KO LD/DL mice, lipid core and thicker cap were detected (Figure 1(c)).

3.2. Serum Lipid Level and Rhythm. We evaluated the serum lipid levels in mouse samples every $4 \mathrm{~h}$ in the C57, ApoE-KO, and ApoE-KO LD/DL mice at ZT0, ZT4, ZT8, ZT12, ZT16, and ZT20 (ZT0 corresponds to "lights on" and ZT12 to "light off') (Table 2).

As shown in Figure 2, the total triglyceride (TG), total cholesterol (TC), and low-density lipoprotein (LDL) levels in ApoE-KO LD/DL mice were significantly increased compared with the C57 and ApoE-KO mice. Further, the mesors and amplitudes of TG, TC, HDL, and LDL were enhanced in ApoE-KO LD/DL mice compared with C57 mice and ApoEKO mice. These results indicated that irregular light-dark interval aggravated the changes of lipid levels and oscillation patterns in ApoE-KO LD/DL mice.

3.3. Diurnal Expression Patterns of Circadian Genes in Liver and Fat. Liver and fat play an important role in energy metabolism. Abnormal energy metabolism increases the risk for atherosclerosis. Most of the clock genes exhibit circadian expression not only in SCN but also in peripheral tissues including liver and fat. To explore the possible changes in clock gene expression in atherosclerotic liver and fat, we performed real-time PCR analysis and compared the expression levels of the core clock genes in liver and fat, including Bmal1, Cry1, Per2, and Rev-erb $\alpha$, in the three groups (C57, 
TABLE 2: Circadian rhythmic parameters of triglyceride, total cholesterol, HDL cholesterol, and LDL cholesterol levels in serum.

\begin{tabular}{lccc}
\hline Serum lipid & Mesor & Amplitude & Acrophase ZT (h) \\
\hline C57 ND & & & \\
Triglyceride & $0.81 \pm 0.12$ & $0.10 \pm 0.04$ & $11.95 \pm 0.90$ \\
Total cholesterol & $1.93 \pm 0.12$ & $0.12 \pm 0.06$ & $13.37 \pm 0.72$ \\
HDL cholesterol & $1.50 \pm 0.18$ & $0.14 \pm 0.04$ & $13.75 \pm 0.07$ \\
LDL cholesterol & $0.11 \pm 0.02$ & $0.04 \pm 0.01$ & $13.33 \pm 0.13$ \\
\hline ApoE-KO & & & $8.17 \pm 0.17$ \\
Triglyceride & $1.61 \pm 0.16^{* *}$ & $0.43 \pm 0.06^{* *}$ & $10.12 \pm 0.25^{*}$ \\
Total cholesterol & $10.05 \pm 0.81^{* *}$ & $1.27 \pm 0.31^{*}$ & $12.34 \pm 0.27$ \\
HDL cholesterol & $1.87 \pm 0.11^{*}$ & $0.21 \pm 0.04$ & $10.81 \pm 0.13^{* *}$ \\
LDL cholesterol & $6.63 \pm 0.71^{* *}$ & $0.73 \pm 0.27^{*}$ & $11.15 \pm 0.11$ \\
ApoE-KO LD/DL & & & $8.48 \pm 0.08^{* *}$ \\
Triglyceride & $2.81 \pm 0.16^{* * \# \#}$ & $12.80 \pm 0.15$ \\
Total cholesterol & $20.27 \pm 1.82^{* * \# \#}$ & $0.91 \pm 0.02^{* * \# \#}$ & $13.21 \pm 0.05^{\# \#}$ \\
HDL cholesterol & $3.28 \pm 0.22^{* * \# \#}$ & $7.26 \pm 0.42^{* * \# \#}$ & $0.63 \pm 0.13^{* * \# \#}$ \\
LDL cholesterol & $27.13 \pm 2.08^{* * \# \#}$ & $4.79 \pm 0.49^{* * \# \#}$ & \\
\hline
\end{tabular}

$n=4 .{ }^{*} P<0.05,{ }^{* *} P<0.01$ versus C57 mice; ${ }^{\# \#} P<0.01$ versus ApoE-KO mice.

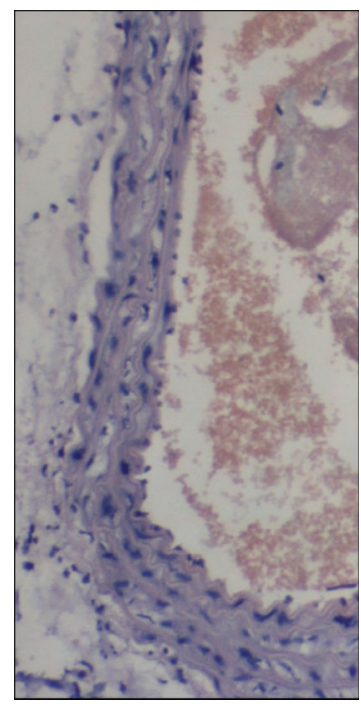

(a)

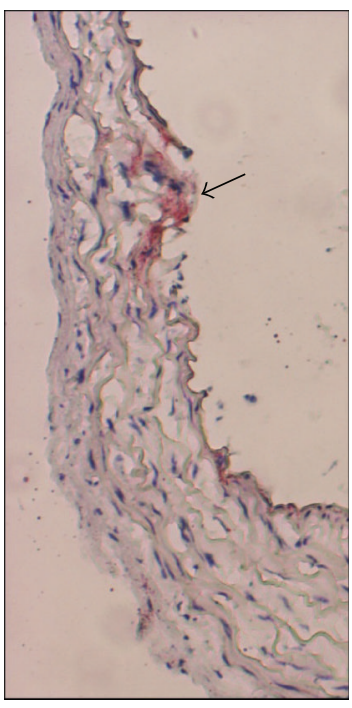

(b)

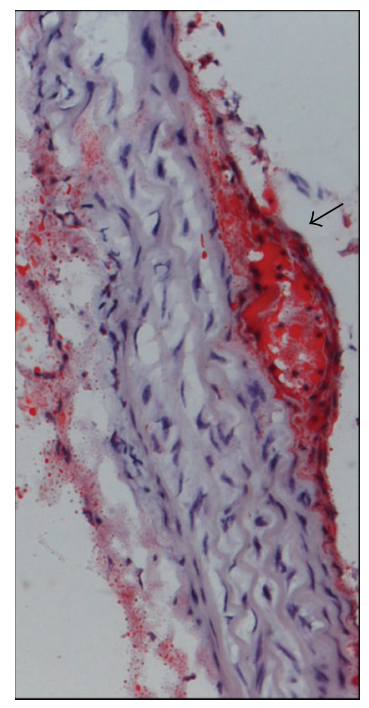

(c)

FIGURE 1: Oil Red O staining of the aortic arch of mice. We used Oil Red O staining to evaluate vulnerable plaques in the wild type C57 BL/6J (C57) mice, the ApoE knockout (ApoE-KO) mice treated with regular light-dark conditions, and the ApoE-KO (ApoE-KO LD/DL) mice with abnormal light stimulation. The arterial arch of C57, ApoE-KO, and ApoE-KO LD/DL mice was dyed with Oil Red O. No obvious changes were found in the C57 group (a). Endothelial lipid deposition and foam cell formation were seen in ApoE-KO group (b). However, exposure to abnormal day and night for 6 weeks resulted in lipid core and thicker caps were detected in ApoE-KO LD/DL mice (c). Arrowheads indicate lipid deposition. Original magnification $\times 200(n=4)$.

ApoE-KO, and ApoE-KO LD/DL) of mice at ZT0, ZT4, ZT8, ZT12, ZT16, and ZT20 as shown in Figures 3 and 4.

In the liver tissues, these four clock genes exhibited a significant $24 \mathrm{~h}$ circadian expression pattern (Figure 3 ). The mesors of Bmal1 and Per2 were reduced in ApoE-KO LD/DL mice compared with those in $\mathrm{C} 57$ and ApoE-KO mice. The amplitudes of Cryl in ApoE-KO mice and ApoE-KO LD/DL mice were decreased compared with those in C57 mice, and the amplitudes of Per2 and Rev-erb $\alpha$ in ApoE-KO LD/DL mice were attenuated compared with those in ApoE-KO mice. The acrophases of Bmall, Cryl, and Per2 in ApoE-KO $\mathrm{LD} / \mathrm{DL}$ mice were altered compared with those in C57 and ApoE-KO mice (Table 3).

In fat tissue, the circadian rhythmicity was lost in Bmall of ApoE-KO LD/DL mice and in Cryl of ApoE-KO and ApoEKO LD/DL mice (Figure 4). The mesors were reduced of those 

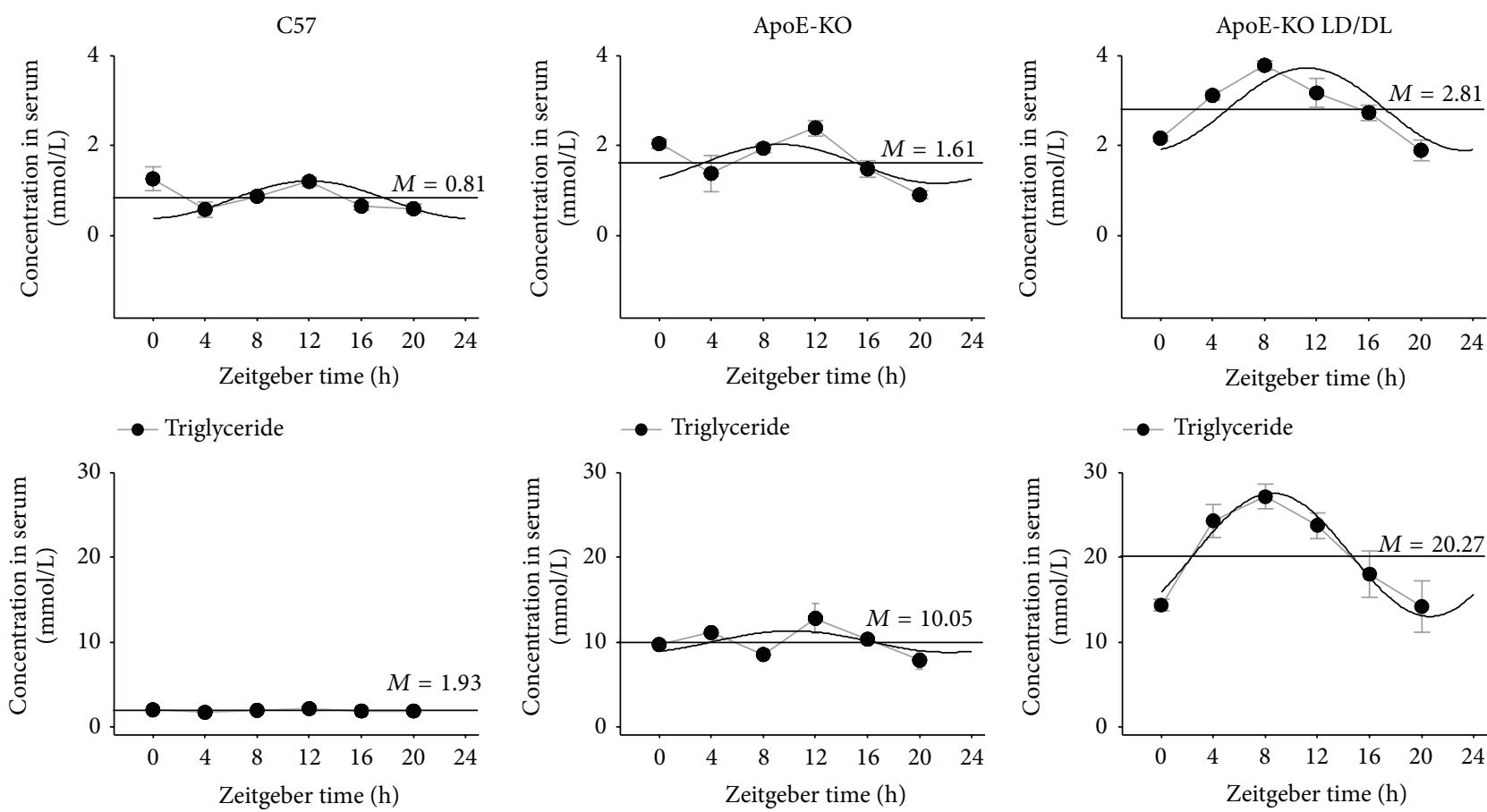

- Triglyceride

- Triglyceride
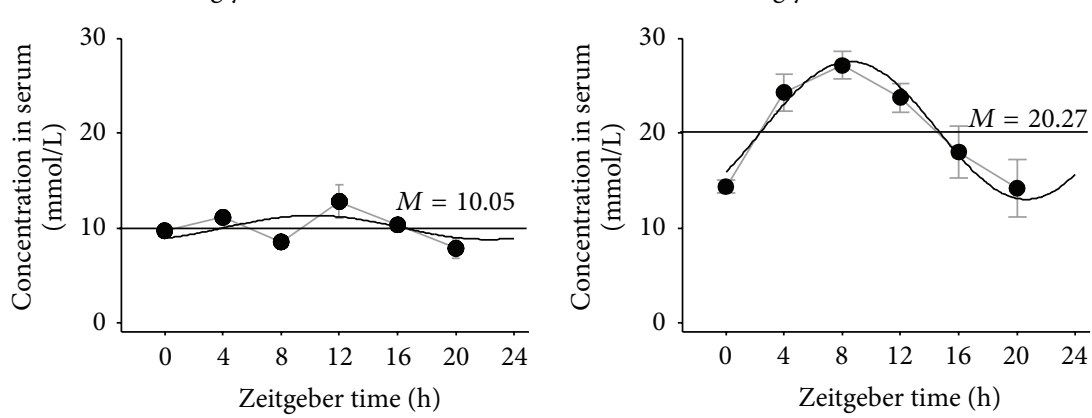

- Total cholesterol

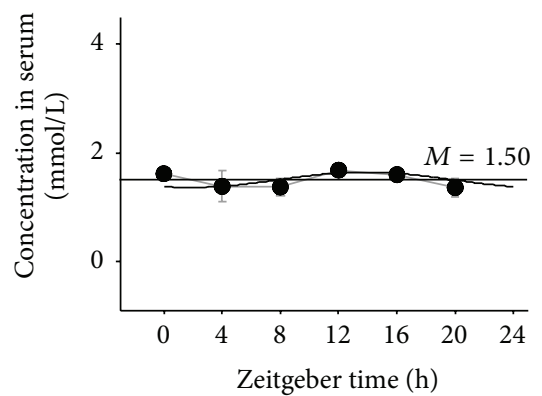

- Total cholesterol

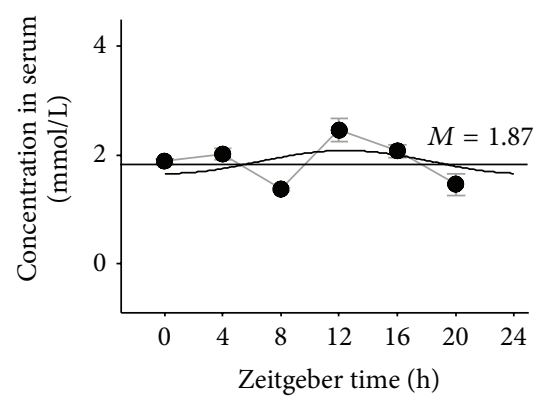

- Total cholesterol

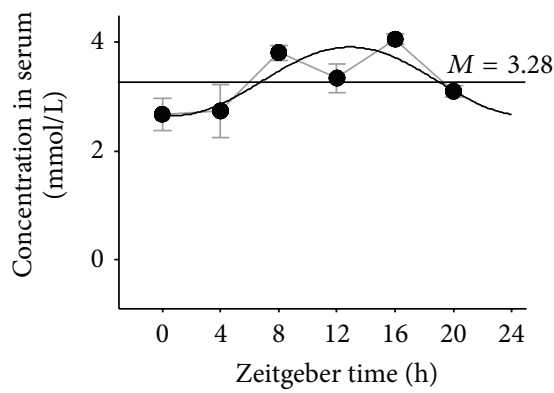

- HDL cholesterol

- HDL cholesterol
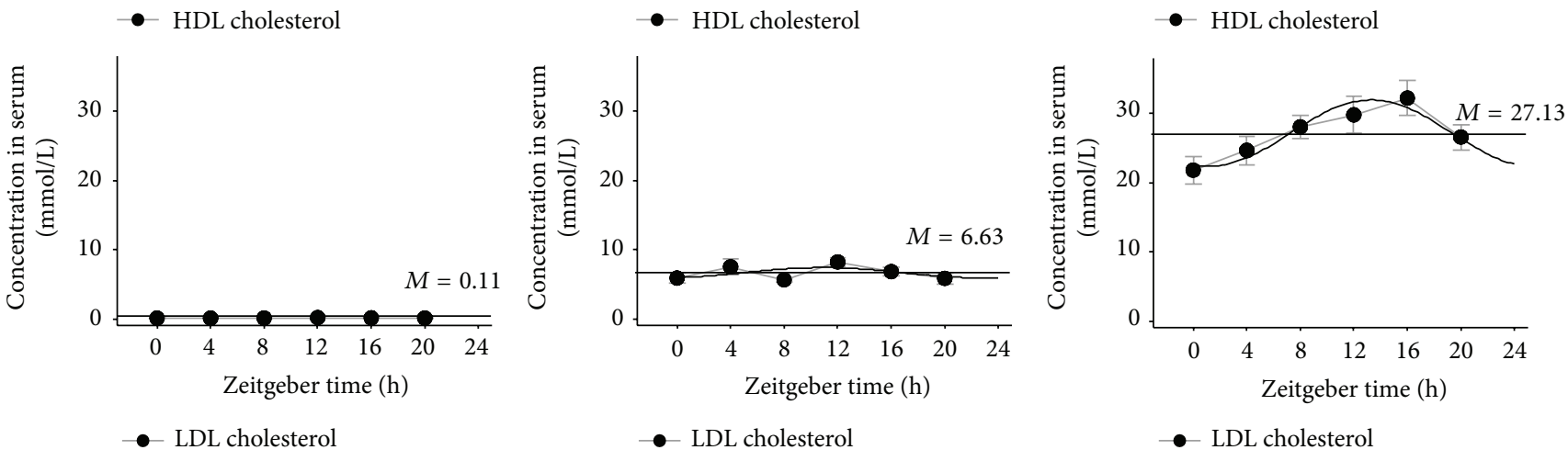

FIGURE 2: Serum total triglyceride, cholesterol, HDL-CHO, and LDL-CHO of blood in mice. We collected the blood of mice in three groups at ZT0, ZT4, ZT8, ZT12, ZT16, and ZT20. The total triglyceride (TG), total cholesterol (TC), and low-density lipoprotein (LDL) levels in ApoE-KO LD/DL mice were significantly increased compared with the C57 and ApoE-KO mice. Further, the mesors and amplitudes of TG, TC, HDL, and LDL were enhanced in ApoE-KO LD/DL mice compared with C57 mice and ApoE-KO mice $(n=4$ for each group at every time point).

four clock genes in ApoE-KO LD/DL mice compared with C57 mice. The amplitude of Per2 in ApoE-KO LD/DL mice was significantly decreased compared with C57 and ApoEKO mice. Further, the acrophases of Rev-erb $\alpha$ were delayed in ApoE-KO LD/DL mice compared with those in C57 mice. Generally, the expression of Bmall and Per2 in ApoE-KO $\mathrm{LD} / \mathrm{DL}$ mice was significantly decreased compared with that in C57 mice and in ApoE-KO mice (Table 4). Overall, our data 


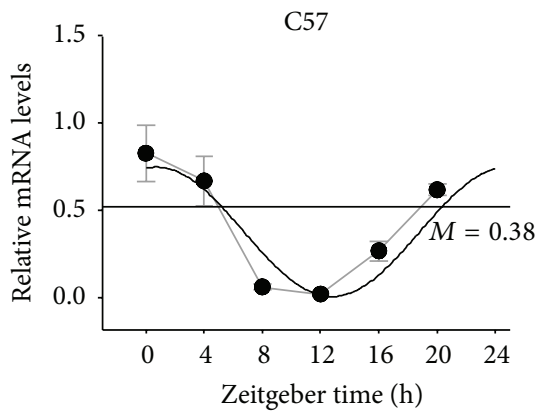

- Bmall

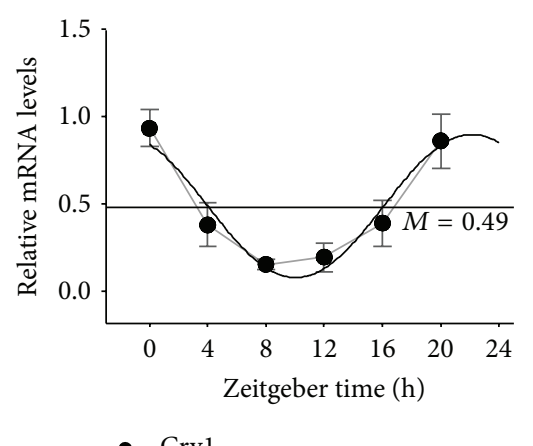

- Cryl

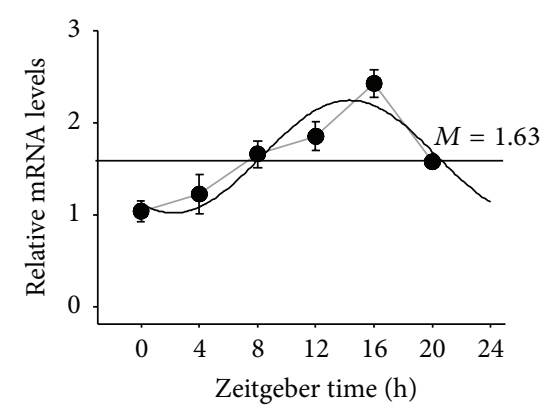

- Per2

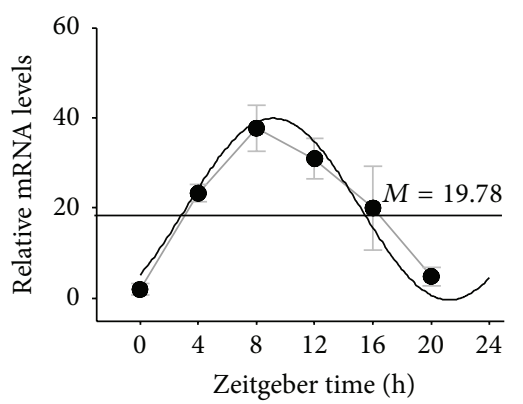

- Rev-erb $\alpha$

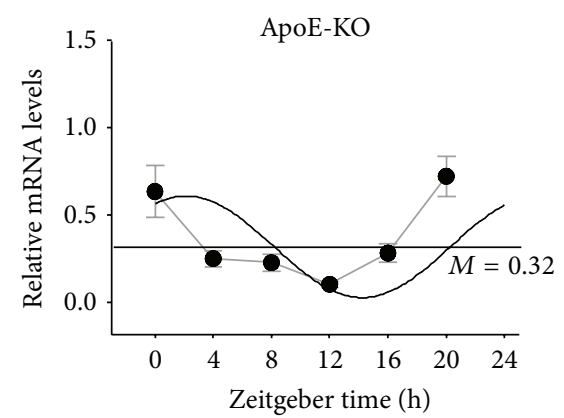

- Bmall
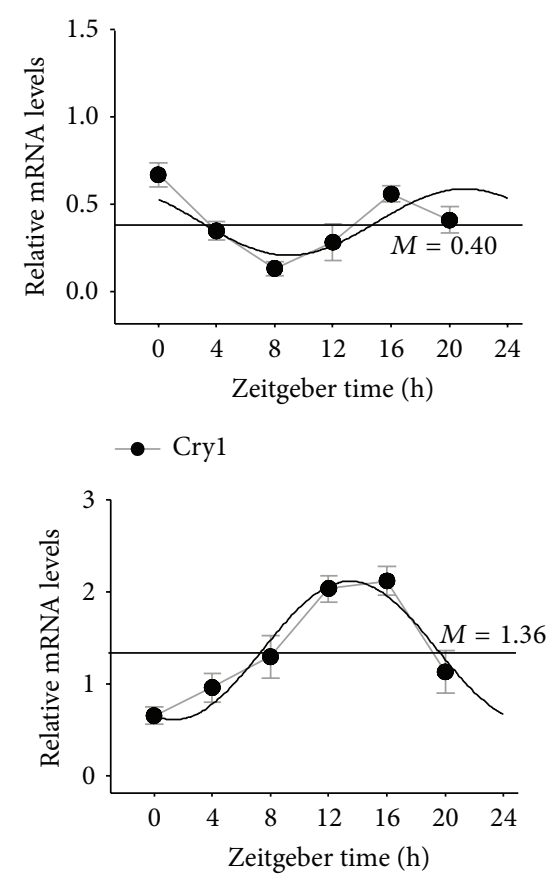

- Per2

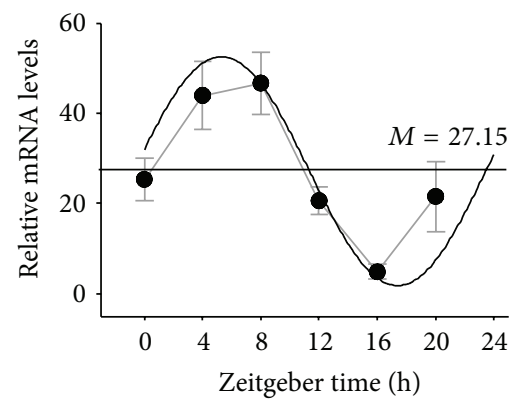

- Rev-erb $\alpha$

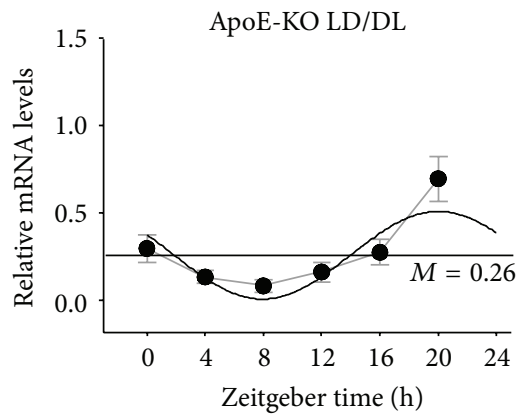

- Bmall
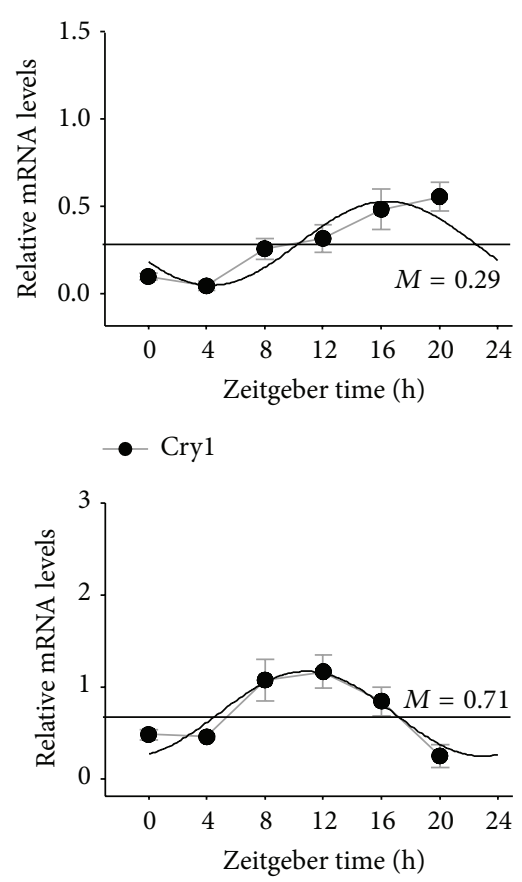

- Per2

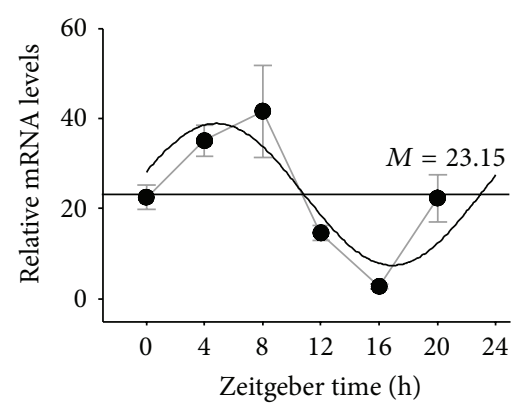

- Rev-erb $\alpha$

FIGURE 3: Circadian expression of clock genes in liver of C57, ApoE-KO, and ApoE-KO LD/DL mice. We obtained the liver tissues of mice at time points of ZT0, ZT4, ZT8, ZT12, ZT16, and ZT20. Levels of mRNA were determined by quantitative real-time PCR. In the liver tissue, the four clock genes Bmal1, Per2, Cryl, and Rev-erb $\alpha$ exhibit significant 24 h circadian expression pattern in C57, ApoE-KO, and ApoE-KO LD/DL mice. The mesors of Bmall and Per2 were reduced in ApoE-KO LD/DL mice compared with those in C57 and ApoE-KO mice. The amplitudes of Cryl in ApoE-KO mice and ApoE-KO LD/DL mice were decreased compared with those in C57 mice, and the amplitudes of Per 2 and Rev-erb $\alpha$ in ApoE-KO LD/DL mice were attenuated compared with those in ApoE-KO mice. The acrophases of Bmall, Cryl, and Per2 in ApoE-KO LD/DL mice were altered compared with those in C57 and ApoE-KO mice. The mRNA levels of clock genes were normalized to $G A P D H$ mRNA ( $n=4$ for each group at every time point). 

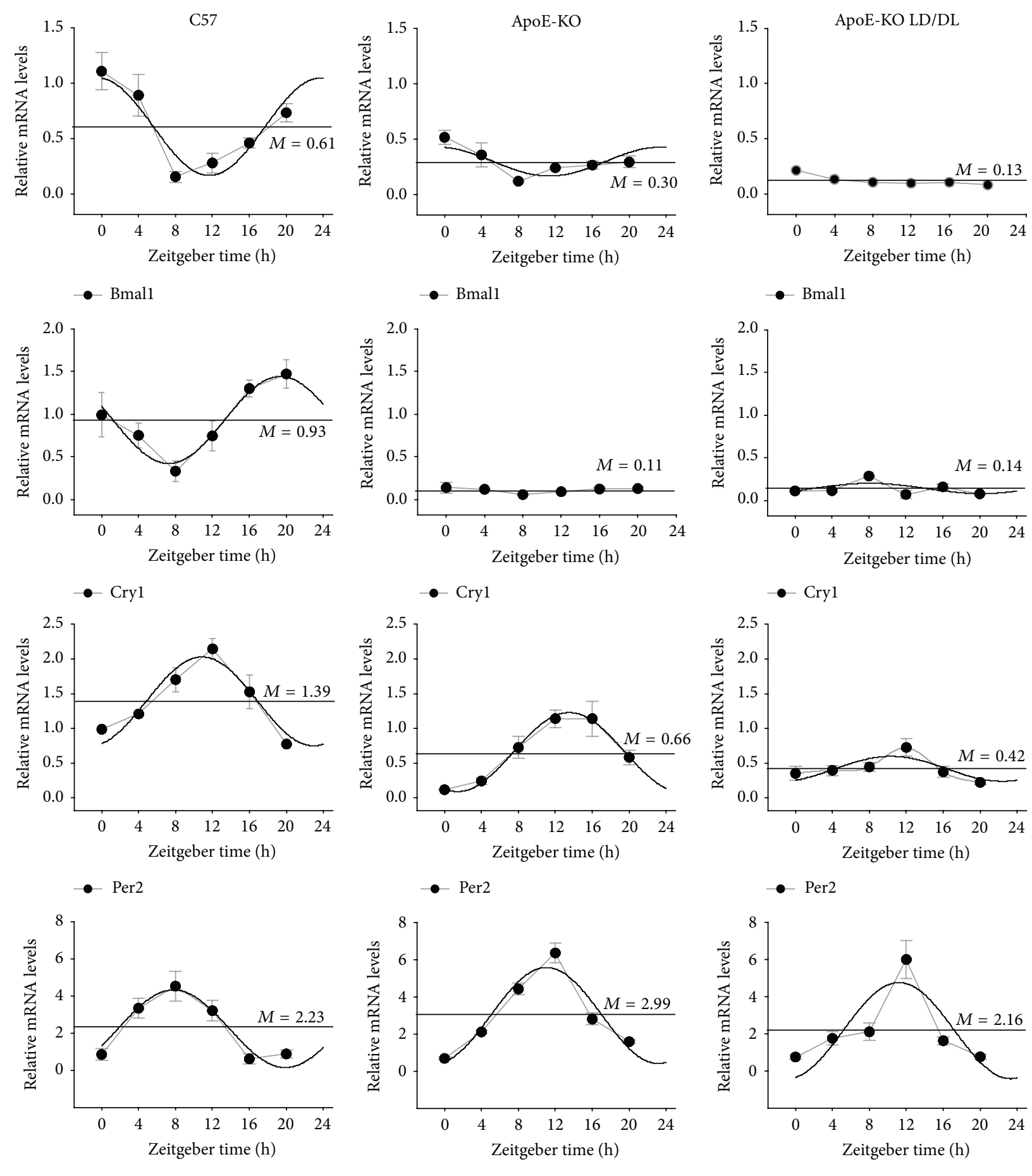

FIgURE 4: Circadian expression of clock genes in fat of C57, ApoE-KO, and ApoE-KO LD/DL mice. We obtained the epididymal fat tissues of mice at time points of ZT0, ZT4, ZT8, ZT12, ZT16, and ZT20. Levels of mRNA were determined by quantitative real-time PCR. In the epididymal fat tissue, circadian rhythm was lost in Bmall of ApoE-KO LD/DL mice and Cryl of both ApoE-KO and ApoE-KO LD mice. The mesors were reduced of those four clock genes in ApoE-KO LD/DL mice compared with C57 mice. The amplitude of Per2 in ApoE-KO LD/DL mice was significantly decreased compared with C57 and ApoE-KO LD/DL mice. The acrophases of Rev-erb $\alpha$ were delayed in ApoE$\mathrm{KO} \mathrm{LD} / \mathrm{DL}$ mice compared with those in C57. The mRNA levels of clock genes were normalized to GAPDH mRNA ( $n=4$ for each group at every time point). 
TABLE 3: Circadian rhythmic parameters of clock genes, $\operatorname{PPAR} \alpha, \operatorname{PPAR} \gamma, \operatorname{ROR} \alpha, \operatorname{RXR} \alpha$, and Sirtl in mouse liver.

\begin{tabular}{|c|c|c|c|}
\hline Gene & Mesor & Amplitude & Acrophase ZT (h) \\
\hline \multicolumn{4}{|l|}{ C57 ND } \\
\hline Bmal1 & $0.38 \pm 0.02$ & $0.37 \pm 0.05$ & $0.69 \pm 0.06$ \\
\hline Cryl & $0.49 \pm 0.03$ & $0.41 \pm 0.04$ & $21.98 \pm 0.15$ \\
\hline Per2 & $1.63 \pm 0.08$ & $0.61 \pm 0.20$ & $14.20 \pm 0.25$ \\
\hline Rev-erb $\alpha$ & $19.78 \pm 5.65$ & $20.12 \pm 7.8$ & $9.09 \pm 0.49$ \\
\hline $\operatorname{PPAR} \alpha$ & $1.45 \pm 0.09$ & $0.77 \pm 0.06$ & $11.00 \pm 0.07$ \\
\hline $\operatorname{PPAR} \gamma$ & $1.75 \pm 0.36$ & $0.97 \pm 0.36$ & $13.90 \pm 0.17$ \\
\hline $\operatorname{ROR} \alpha$ & $1.28 \pm 0.10$ & $0.48 \pm 0.04$ & $12.42 \pm 0.12$ \\
\hline $\operatorname{RXR} \alpha$ & $1.77 \pm 0.15$ & $0.53 \pm 0.05$ & $6.38 \pm 1.42$ \\
\hline Sirtl & $0.79 \pm 0.04$ & $0.39 \pm 0.05$ & $23.16 \pm 0.06$ \\
\hline \multicolumn{4}{|l|}{ ApoE-KO } \\
\hline Bmal1 & $0.32 \pm 0.03$ & $0.29 \pm 0.06$ & $0.38 \pm 0.04$ \\
\hline Cryl & $0.40 \pm 0.07$ & $0.19 \pm 0.02^{* *}$ & $21.32 \pm 0.06$ \\
\hline Per2 & $1.36 \pm 0.13^{* *}$ & $0.75 \pm 0.12$ & $13.31 \pm 0.10$ \\
\hline Rev-erb $\alpha$ & $27.15 \pm 3.92^{*}$ & $25.33 \pm 6.63$ & $4.98 \pm 0.10^{* *}$ \\
\hline $\operatorname{PPAR} \alpha$ & $2.00 \pm 0.16^{* *}$ & $1.67 \pm 0.10^{* *}$ & $15.20 \pm 0.06^{* *}$ \\
\hline $\operatorname{PPAR} \gamma$ & $9.02 \pm 0.36^{* *}$ & $5.01 \pm 0.66^{* *}$ & $12.80 \pm 0.05$ \\
\hline $\operatorname{ROR} \alpha$ & $0.63 \pm 0.05^{* *}$ & $0.21 \pm 0.03^{* *}$ & $11.99 \pm 0.11$ \\
\hline $\operatorname{RXR} \alpha$ & $1.95 \pm 0.11$ & $0.69 \pm 0.23$ & $7.22 \pm 0.08$ \\
\hline Sirt1 & - & - & - \\
\hline \multicolumn{4}{|c|}{ ApoE-KO LD/DL } \\
\hline Bmall & $0.26 \pm 0.04^{* * \# \#}$ & $0.25 \pm 0.09$ & $19.87 \pm 0.03^{* * \# \#}$ \\
\hline Cryl & $0.29 \pm 0.02^{* *}$ & $0.24 \pm 0.04^{* *}$ & $16.27 \pm 0.10^{* * \# \#}$ \\
\hline Per2 & $0.71 \pm 0.06^{* * \# \#}$ & $0.46 \pm 0.08^{\#}$ & $10.77 \pm 0.08^{* \# \#}$ \\
\hline Rev-erb $\alpha$ & $23.15 \pm 2.42$ & $15.7 \pm 2.30^{\#}$ & $4.78 \pm 0.07^{* *}$ \\
\hline $\operatorname{PPAR} \alpha$ & $2.06 \pm 0.06^{* *}$ & $1.61 \pm 0.02^{* *}$ & $7.87 \pm 0.02^{* * \# \#}$ \\
\hline $\operatorname{PPAR} \gamma$ & $6.72 \pm 0.10^{* * \# \#}$ & $4.89 \pm 0.07^{* *}$ & $7.64 \pm 0.02^{* * \# \#}$ \\
\hline $\operatorname{ROR} \alpha$ & $0.66 \pm 0.02^{* *}$ & $0.19 \pm 0.02^{* *}$ & $14.17 \pm 0.02^{* \# \#}$ \\
\hline $\operatorname{RXR} \alpha$ & $1.96 \pm 0.05$ & $0.44 \pm 0.01$ & $9.13 \pm 0.05^{* * \#}$ \\
\hline Sirtl & - & - & - \\
\hline
\end{tabular}

indicated that the abnormal day-night exposure aggravated the circadian genes expression disorder in liver and fat tissues of ApoE-KO LD/DL mice.

3.4. Diurnal Expression Pattern of PPAR $\alpha, P P A R \gamma, R O R \alpha$, and $R X R \alpha$ in Liver and Fat. Altered circadian gene expression contributed to changes in expression patterns of a series of downstream clock-controlled genes. Therefore, using quantitative RT-PCR, we examined the expression of $P P A R \alpha$, $P P A R \gamma, R O R \alpha$, and $R X R \alpha$ in liver and fat of atherosclerotic mice.

As shown in Figure 5, in the liver tissue, the mesors of PPAR $\alpha$ and PPAR $\gamma$ in ApoE-KO mice and ApoE-KO $\mathrm{LD} / \mathrm{DL}$ mice were improved compared with those in C57 mice. The amplitudes of PPAR $\alpha$ and PPAR $\gamma$ were enhanced while the amplitudes of $R O R \alpha$ were attenuated in ApoE-KO mice and ApoE-KO LD/DL mice compared with C57 mice. The acrophases of PPAR $\alpha$ and PPAR $\gamma$ were advanced and the acrophase of $R X R \alpha$ was delayed in ApoE-KO LD/DL mice compared with $\mathrm{C} 57$ and ApoE-KO mice. The expression levels of PPAR $\alpha$ and PPAR $\gamma$ in ApoE-KO LD/DL mice were increased compared with C57 mice (Table 3).

In the fat tissue, PPAR $\gamma$ in ApoE-KO LD/DL mice and $R X R \alpha$ in C57 mice exhibited circadian oscillation not in accordance with 24 hours, and PPAR $\gamma$ in ApoE-KO mice, $R O R \alpha$ in $\mathrm{C} 57$ and ApoE-KO mice, and RXR $\alpha$ in ApoE-KO mice did not well fit the cosine curves (Figure 6). The mesor of PPAR $\alpha$ was enhanced in ApoE-KO LD/DL mice compared with those in C57 and ApoE-KO mice (Table 4). These results indicated that the oscillation of lipid metabolism-associated genes PPAR $\alpha, P P A R \gamma, R O R \alpha$, and $R X R \alpha$ was altered.

3.5. Diurnal Expression Pattern of Sirt1 in Liver and Fat. Sirtuin 1 (Sirt1), a nuclear protein, regulates liver and fat metabolism, and its HDAC activity also exhibits circadian oscillation in liver tissue [21]. We detected the Sirt1 expression patterns in liver and fat as shown in Figure 7. In the liver tissue, Sirt1 in ApoE-KO and ApoE-KO LD/DL mice exhibited circadian oscillation not in accordance with 24 hours. Further, in the fat tissue, the mesors of ApoE-KO mice and 
TABLE 4: Circadian rhythmic parameters of clock genes, $\operatorname{PPAR} \alpha, \operatorname{PPAR} \gamma, \operatorname{ROR} \alpha, \operatorname{RXR} \alpha$, and Sirtl in mouse fat.

\begin{tabular}{|c|c|c|c|}
\hline Gene & Mesor & Amplitude & Acrophase ZT (h) \\
\hline \multicolumn{4}{|l|}{ C57 ND } \\
\hline Bmal1 & $0.61 \pm 0.04$ & $0.44 \pm 0.05$ & $23.58 \pm 0.09$ \\
\hline Cryl & $0.93 \pm 0.01$ & $0.51 \pm 0.04$ & $19.22 \pm 0.12$ \\
\hline Per2 & $1.39 \pm 0.08$ & $0.64 \pm 0.08$ & $10.77 \pm 0.08$ \\
\hline Rev-erb $\alpha$ & $2.23 \pm 0.14$ & $2.08 \pm 0.19$ & $7.75 \pm 0.01$ \\
\hline $\operatorname{PPAR} \alpha$ & $7.34 \pm 0.16$ & $6.83 \pm 0.29$ & $12.1 \pm 0.03$ \\
\hline $\operatorname{PPAR} \gamma$ & $1.25 \pm 0.05$ & $0.68 \pm 0.05$ & $15.55 \pm 0.03$ \\
\hline $\operatorname{ROR} \alpha$ & - & - & - \\
\hline RXR X & - & - & - \\
\hline Sirt1 & $7.24 \pm 0.24$ & $7.18 \pm 0.28$ & $6.33 \pm 0.01$ \\
\hline \multicolumn{4}{|l|}{ ApoE-KO } \\
\hline Bmall & $0.30 \pm 0.03^{* *}$ & $0.13 \pm 0.03^{* *}$ & $23.27 \pm 0.15$ \\
\hline Cryl & - & - & - \\
\hline Per2 & $0.66 \pm 0.01^{* *}$ & $0.57 \pm 0.09$ & $13.41 \pm 0.06^{* *}$ \\
\hline Rev-erb $\alpha$ & $2.99 \pm 0.08^{* *}$ & $2.58 \pm 0.22^{*}$ & $10.96 \pm 0.02^{* *}$ \\
\hline $\operatorname{PPAR} \alpha$ & $11.27 \pm 0.20^{* *}$ & $7.71 \pm 0.10^{* *}$ & $12.68 \pm 0.01$ \\
\hline $\operatorname{PPAR} \gamma$ & - & - & - \\
\hline $\operatorname{ROR} \alpha$ & - & - & - \\
\hline $\operatorname{RXR} \alpha$ & - & - & - \\
\hline Sirtl & $15.27 \pm 0.73^{* *}$ & $9.60 \pm 0.97^{* *}$ & $6.10 \pm 0.02$ \\
\hline \multicolumn{4}{|c|}{ ApoE-KO LD/DL } \\
\hline Bmal1 & - & - & - \\
\hline Cryl & - & - & - \\
\hline Per2 & $0.42 \pm 0.05^{* * \# \#}$ & $0.18 \pm 0.03^{* * \# \#}$ & $10.28 \pm 0.09^{\# \#}$ \\
\hline Rev-erb $\alpha$ & $2.16 \pm 0.18^{* \# \#}$ & $2.01 \pm 0.36^{\#}$ & $11.12 \pm 0.03^{* *}$ \\
\hline $\operatorname{PPAR} \alpha$ & $13.81 \pm 0.33^{* * \# \#}$ & $6.70 \pm 0.05$ & $12.03 \pm 0.02$ \\
\hline $\operatorname{PPAR} \gamma$ & - & - & - \\
\hline $\operatorname{ROR} \alpha$ & $2.01 \pm 0.04$ & $0.84 \pm 0.05$ & $4.79 \pm 0.02$ \\
\hline $\operatorname{RXR} \alpha$ & $1.52 \pm 0.04$ & $0.44 \pm 0.02$ & $2.29 \pm 0.07$ \\
\hline Sirtl & $13.12 \pm 0.10^{* * \#}$ & $7.47 \pm 0.18$ & $5.84 \pm 0.01$ \\
\hline
\end{tabular}

$n=4 .{ }^{*} P<0.05,{ }^{* *} P<0.01$ versus C57 mice; ${ }^{\#} P<0.05,{ }^{\# \#} P<0.01$ versus ApoE-KO mice.

ApoE-KO LD/DL mice were increased compared with those in C57 mice. Concurrently, the expression of ZT0, ZT4, and ZT12 was promoted compared with C57 and ApoE-KO mice. Overall, the circadian oscillation of Sirtl was lost in liver and altered in adipose tissues in ApoE-KO LD/DL mice.

\section{Discussion}

In this study, we investigated the role of abnormal day-night exposure in inducing atherosclerotic plaques in the aortic arch of ApoE-KO LD/DL mice. We also monitored the serum concentration and circadian changes in total triglyceride, total cholesterol, and low-density lipoprotein in ApoE-KO LD/DL mice compared with C57 mice and ApoE-KO mice. Further, the circadian oscillations of clock genes (Bmall, Per2, Cry1, and Rev-erb $\alpha$ ), lipid metabolism-associated genes $(P P A R \alpha, P P A R \gamma, R X R \alpha$, and ROR $\alpha)$, and Sirt1 were modified extensively in ApoE-KO LD/DL mice compared with those in $\mathrm{C} 57$ mice and ApoE-KO mice.
Atherosclerosis is a chronic disease caused by multiple factors. The risk factors include hyperlipidemia, hypertension, smoking, diabetes, vascular inflammation, and autoimmune disease. High lipid levels, especially LDL, increase the risk of atherosclerosis [32, 33]. Therefore, we sought to identify the circadian alteration in clock genes and lipid metabolism-related genes altered in the liver and fat of atherosclerotic mice.

ApoE-KO mouse is an ideal model of atherosclerosis, in which total serum cholesterol and low-density lipoprotein levels are significantly higher than in C57 mice of the same sex. Further, ApoE-KO mice displayed significant atherosclerotic plaques in the aorta at six months [34]. Our preliminary studies also showed that, in 10-week-old male ApoE-KO mice fed with Western diet and exposed to chaotic light for six weeks, significant atherosclerotic plaques formed [30]. Further, the amplitudes of circadian oscillations in serum lipids were increased significantly with higher lipid levels. However, under similar conditions no obvious pathological changes in 

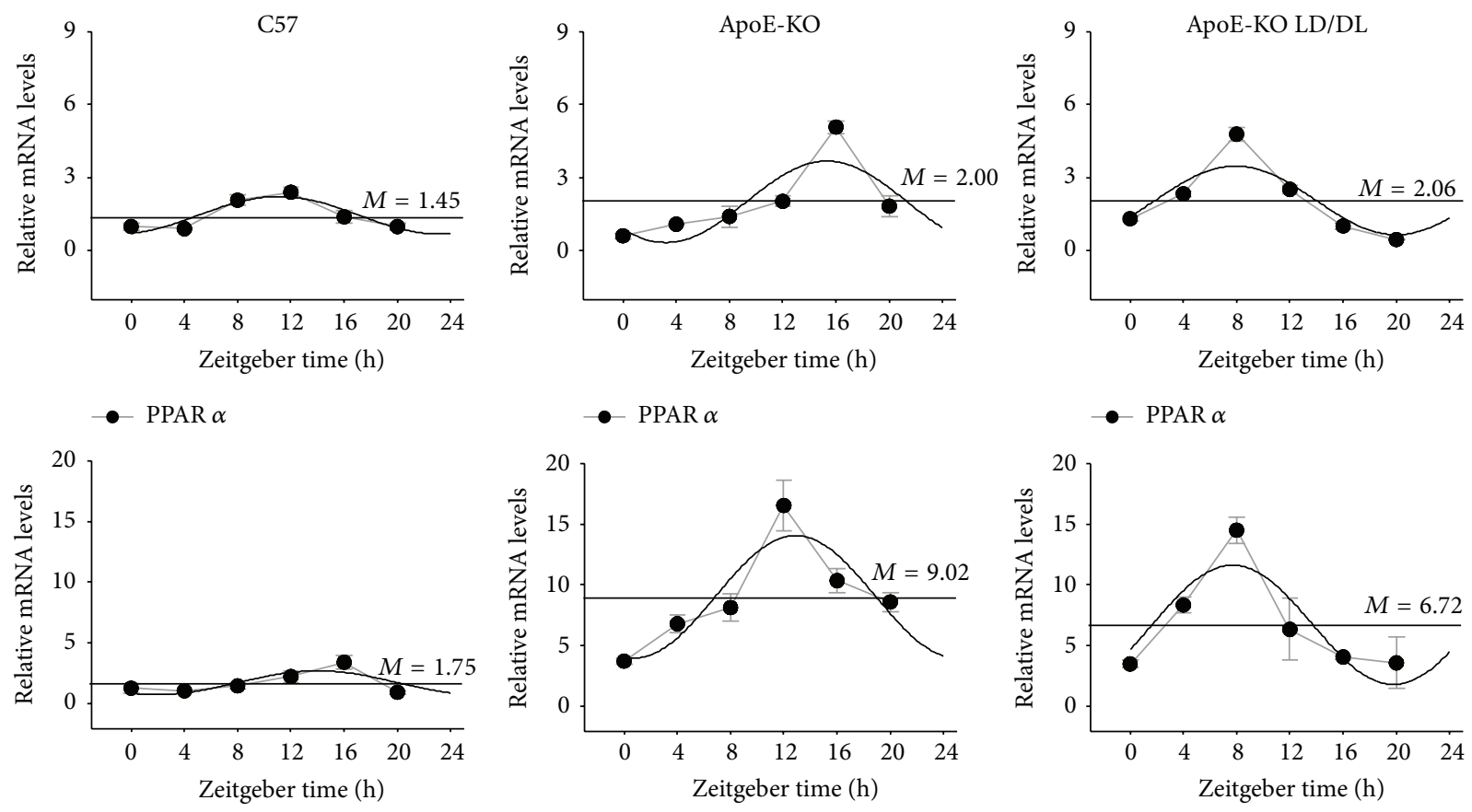

$\bullet \operatorname{PPAR} \gamma$

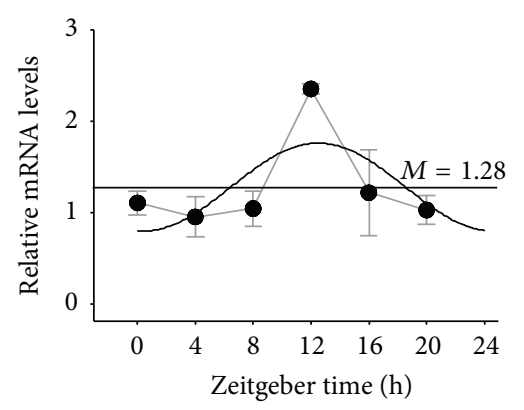

- $\operatorname{PPAR} \gamma$

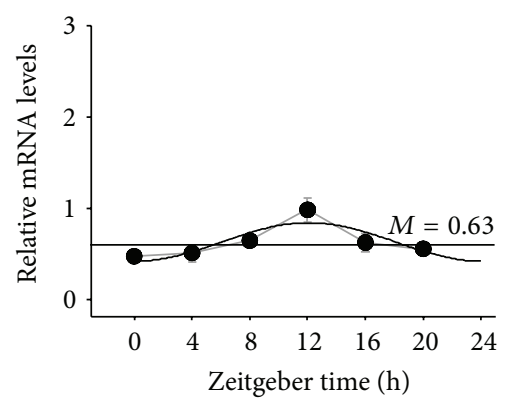

- $\operatorname{PPAR} \gamma$

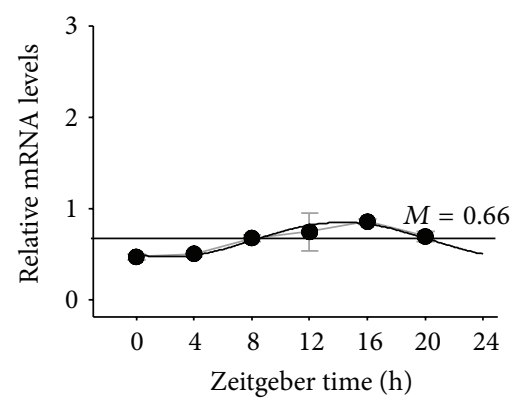

- $\operatorname{ROR} \alpha$

- $\operatorname{ROR} \alpha$
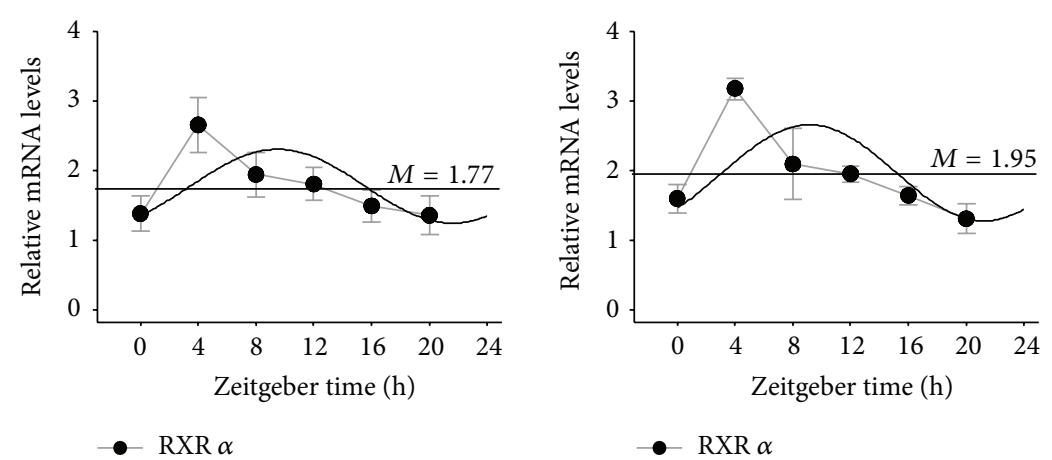

- $\operatorname{ROR} \alpha$

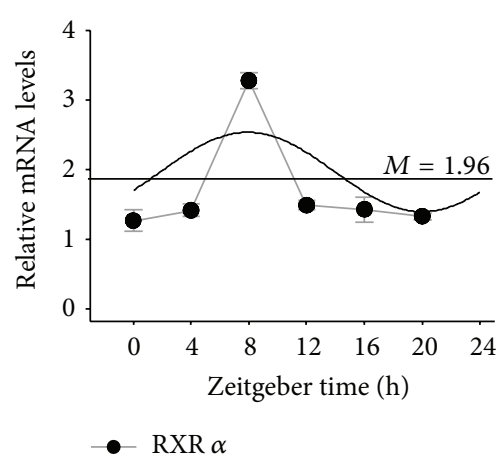

Figure 5: Circadian expression of PPAR $\alpha, P P A R \gamma, R O R \alpha$, and $R X R \alpha$ in mouse liver tissues. We also identified the diurnal expression of lipid metabolism-associated genes (PPAR $\alpha, P P A R \gamma, R O R \alpha$, and $R X R \alpha)$ in liver at specific time points. Levels of mRNA were determined by quantitative real-time PCR. The mesors of PPAR $\alpha$ and PPAR $\gamma$ in ApoE-KO mice and ApoE-KO LD/DL mice were improved compared with those in C57 mice. The amplitudes of PPAR $\alpha$ and PPAR $\gamma$ were enhanced and the amplitudes of ROR $\alpha$ were attenuated in ApoE-KO mice and ApoE-KO LD/DL mice compared with C57 mice. The acrophases of PPAR $\alpha$ and PPAR $\gamma$ were advanced and the acrophase of RXR $\alpha$ was delayed in ApoE-KO LD/DL mice compared with C57 and ApoE-KO mice. The expression levels of PPAR $\alpha$ and PPAR $\gamma$ in ApoE-KO $\mathrm{LD} / \mathrm{DL}$ mice were increased compared with C57 mice. The mRNA levels of clock genes were normalized to GAPDH mRNA $(n=4$ for each group at every time point). 

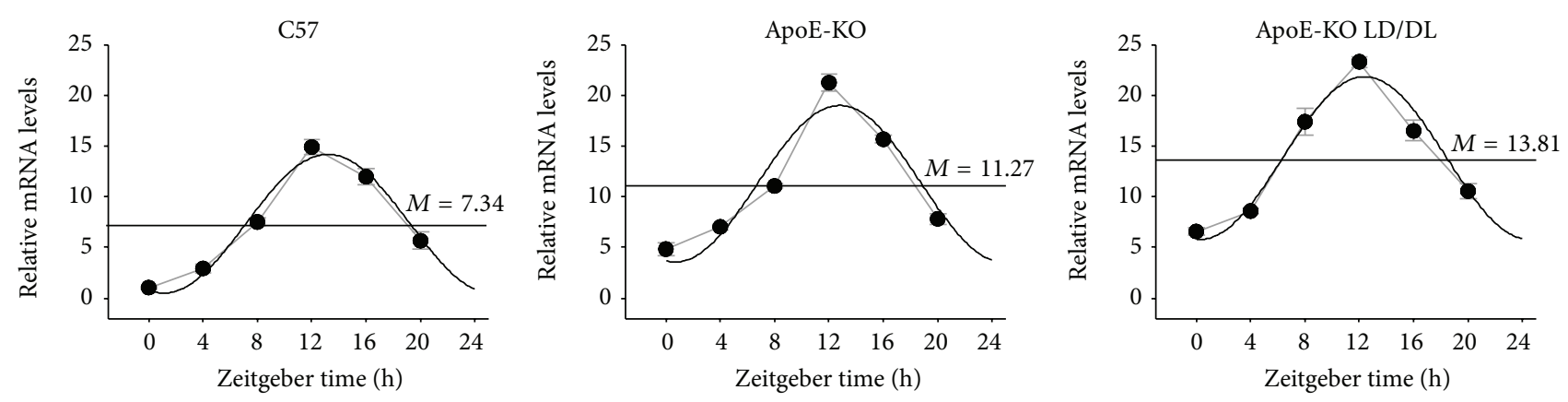

- PPAR $\alpha$

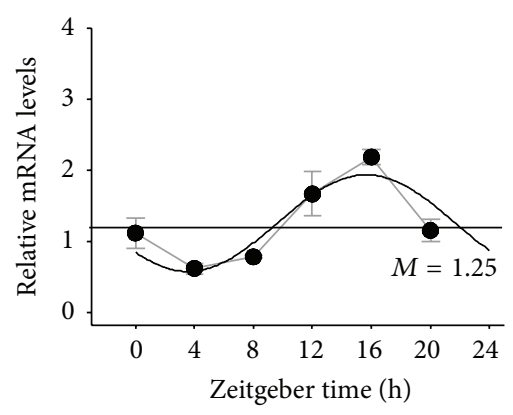

- PPAR $\alpha$

- $\operatorname{PPAR} \alpha$
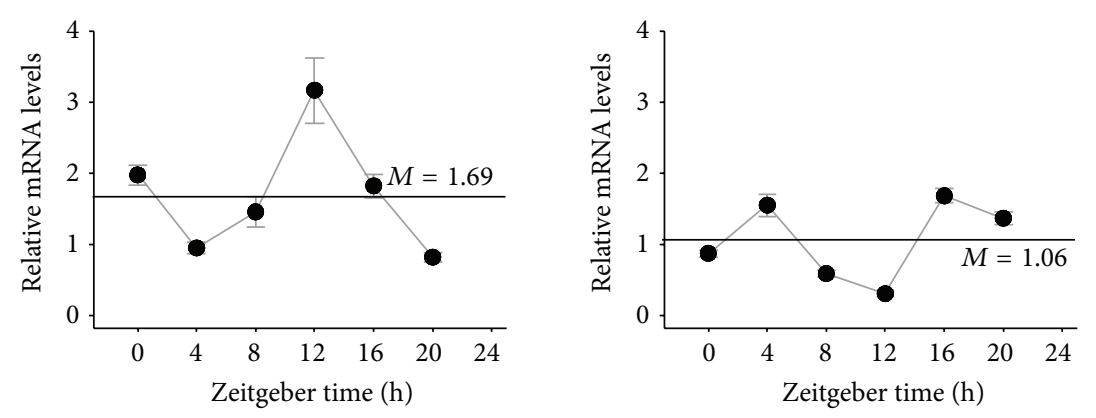

- $\operatorname{PPAR} \gamma$
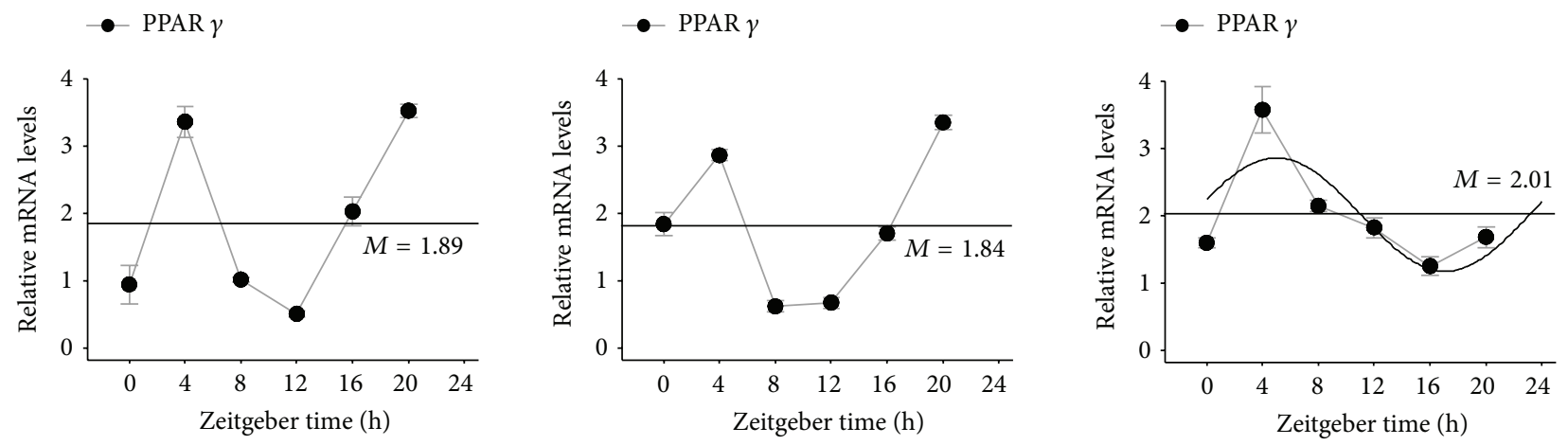

- $\operatorname{ROR} \alpha$

- $\operatorname{ROR} \alpha$

- $\operatorname{ROR} \alpha$
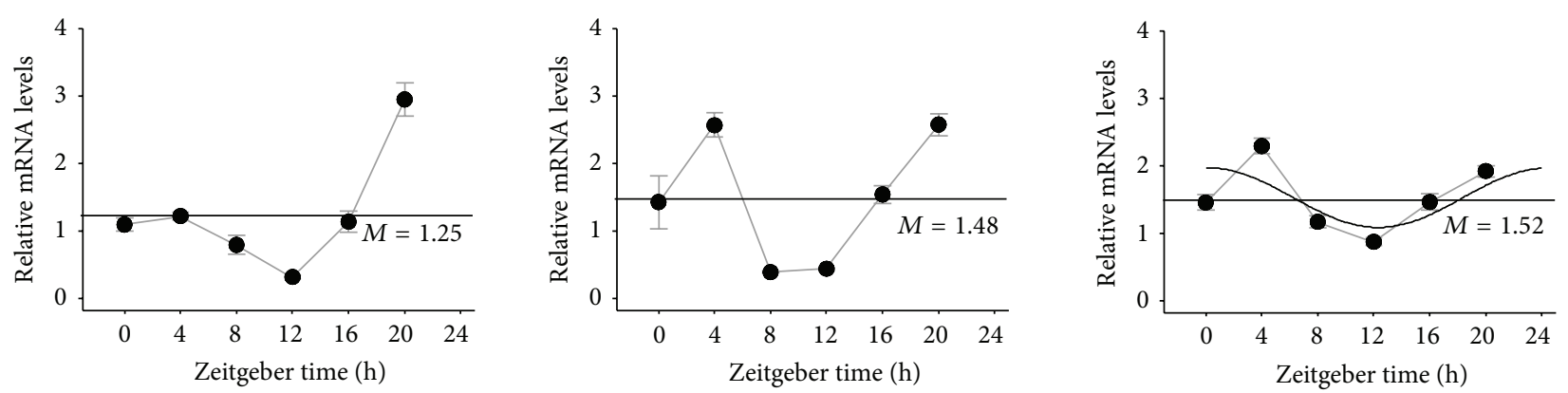

- $\operatorname{RXR} \alpha$

- $\operatorname{RXR} \alpha$

- $\operatorname{RXR} \alpha$

FIgURE 6: Circadian expression of PPAR $\alpha, P P A R \gamma, R O R \alpha$, and $R X R \alpha$ in mouse fat tissues. We also identified the diurnal expression of lipid metabolism-associated genes (PPAR $\alpha, P P A R \gamma, R O R \alpha$, and $R X R \alpha)$ in fat tissue at specific time points. Levels of mRNA were determined by quantitative real-time PCR. In the fat tissue, PPAR $\gamma$ in ApoE-KO LD/DL mice and RXR $\alpha$ in C57 mice exhibited circadian oscillation not in accordance with 24 hours, and PPAR $\gamma$ in ApoE-KO mice, $R O R \alpha$ in C57 and ApoE-KO mice, and $R X R \alpha$ in ApoE-KO mice did not well fit the cosine curves. The mesor of PPAR $\alpha$ was enhanced in ApoE-KO LD/DL mice compared with those in C57 and ApoE-KO mice. The mRNA levels of clock genes were normalized to GAPDH mRNA ( $n=4$ for each group at every time point). 

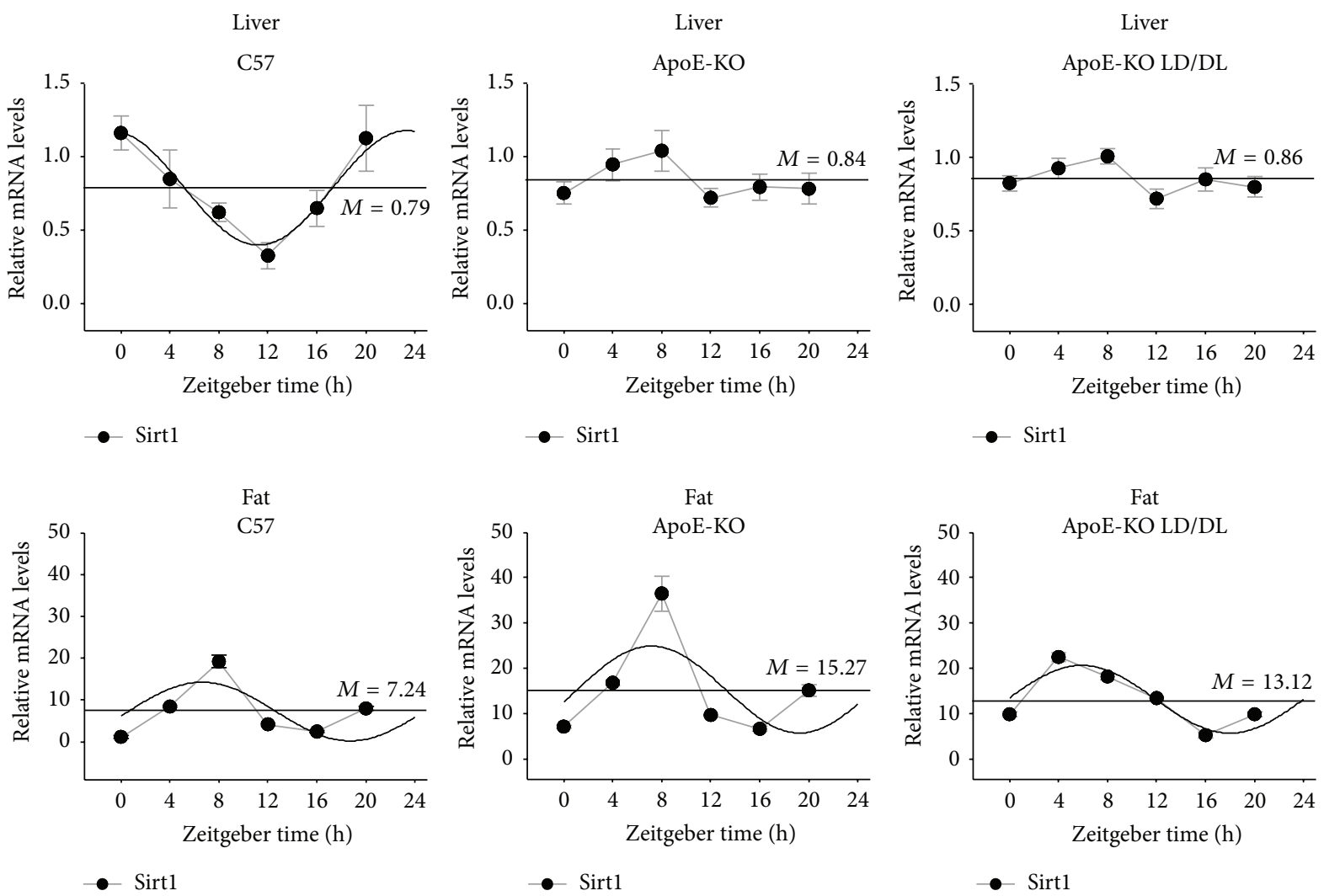

FIguRE 7: Circadian expression of Sirt1 in liver and fat tissue of mice. Levels of Sirt1 were determined by quantitative real-time PCR. In the liver tissue, Sirt1 in ApoE-KO and ApoE-KO LD/DL mice exhibited circadian oscillation not in accordance with 24 hours. Further, in the fat tissue, the mesors of ApoE-KO mice and ApoE-KO LD/DL mice were increased compared with those in C57 mice. The expression of ZT0, ZT4, and ZT12 was promoted compared with C57 and ApoE-KO mice. The mRNA levels of clock genes were normalized to GAPDH mRNA ( $n=4$ for each group at every time point).

aorta were observed in C57 mice of the same sex and age [30]. All those results agreed with our research.

Atherosclerosis is an inflammatory disease involved in accumulating of lipid in the arterial wall. PPAR $\alpha$ and $P P A R \gamma$ control almost all phases of atherosclerosis formation. $P P A R$ $\alpha$ decreased the density of LDL in patients with dyslipidemia [35], and its activation repressed the accumulation of oxidized-LDL in atherosclerotic plaques of insulin-resistant mice [36]. In this study, the total expression level of PPAR $\alpha$ was increased dramatically compared to both in liver and in fat tissue of C57 mice. In addition, the amplitudes of PPAR $\alpha$ were advanced in liver of ApoE-KO LD/DL mice compared with the control groups. PPAR $\gamma$ agonist inhibited phosphorylation of $\mathrm{NF}-\kappa \mathrm{B}$ to repress the inflammatory response $[37,38]$. In atherosclerotic mice, the amplitudes of PPAR $\gamma$ in liver were significantly changed compared with the control groups, and the acrophase was delayed compared with control mice. $R O R \alpha$ has been reported to play important roles in circadian system, adipocyte glyceroneogenesis, and liver gluconeogenesis [39]. It could inhibit NF- $\kappa \mathrm{B}$ activation to attenuate the inflammatory response, which might act as a potent object in the treatment of atherosclerosis [40]. And ROR $\alpha$ was positively correlated with HDL levels [41]. In our study the amplitudes of ROR $\alpha$ in liver were attenuated in ApoE-KO mice and ApoE-KO LD/DL mice compared with C57 mice. Diabetes promotes oxidative stress to aggravate atherosclerosis [42], and $R X R$ agonists postponed the atherosclerosis progression [43]. In liver tissue, the acrophase of $R X R \alpha$ was delayed in ApoE-KO LD/DL mice compared with C57 and ApoE-KO mice. The results indicated that the expression patterns of PPAR $\alpha, P P A R \gamma, R O R \alpha$, and $R X R \alpha$ in mice were altered in ApoE-KO mice, which would promote atherosclerosis progression.

Sirt1 plays a critical role in circadian rhythm and in atherosclerosis. In liver tissue, the rhythms of ApoE-KO and ApoE-KO LD/DL mice were lost. And the mesors of Sirt1 were changed in ApoE-KO LD/DL mice compared with C57. Sirt1 may serve as a link between the clock genes controlling circadian alteration and lipid-related gene oscillation, and its expression disorder might aggravate atherosclerosis. On the other hand, shifted food intake time induced by light at night could eventually lead to obesity in mice [44] and the timing of food intake affected the rhythm of clock genes in liver and other peripheral organs [45]. The timing of feed might be the mechanism of light shifts inducing circadian genes expression disorder and contributing to atherosclerosis. 


\section{Conclusion}

We detected altered expression of the circadian clock genes and lipid metabolism-related genes in liver and fat tissues of atherosclerotic mice manifesting circadian genes expression disorder for the first time. We also observed normal circadian rhythm in Sirt1 expression and its changes in liver and fat tissues of atherosclerotic mice with disordered circadian genes expression. Specific mechanisms underlying the phenomenon remain to be further studied. Our findings provide new research directions and lay a theoretical foundation for further study of the relationship between circadian clock, lipid metabolism disorders, and atherosclerosis.

\section{Abbreviations}

Bmall: $\quad$ Muscle Arnt-like protein 1

Per2: $\quad$ Period 2

Cryl: $\quad$ Cryptochrome 1

Rev-erb $\alpha$ : Nuclear receptor subfamily 1 , group $\mathrm{D}$, member 1

Clock: Circadian locomotor output cycles kaput

SCN: Suprachiasmatic nucleus

ASCVD: Atherosclerotic cardiovascular disease

PPAR $\alpha$ : Proliferator-activated receptors $\alpha$

PPAR $\gamma: \quad$ Proliferator-activated receptors $\gamma$

$\operatorname{ROR} \alpha: \quad$ RAR-related orphan receptor $\alpha$

$\operatorname{RXR} \alpha$ : $\quad$ Retinoid X receptor $\alpha$

Sirtl: $\quad$ Sirtuin 1

qRT-PCR: Quantitative real-time polymerase chain reaction

CCG: $\quad$ Clock-controlled genes

ZT: $\quad$ Zeitgeber time

SREBP-1c: Sterol-regulatory element binding protein $1 \mathrm{c}$

GAPDH: Glyceraldehyde-3-phosphate dehydrogenase.

\section{Ethical Approval}

All procedures were in accordance with the ethical standards of the institution.

\section{Disclosure}

The sponsors had no role in study design, data collection and analysis, decision to publish, or preparation of the paper.

\section{Competing Interests}

The authors have no competing interests to disclose.

\section{Authors' Contributions}

Zhu Zhu and Bingxuan Hua contributed equally to this work as joint first authors. Zhu Zhu, Bingxuan Hua, Xiaobo Li, Ning Sun, Zuoqin Yan, Ruizhe Qian, and Chao Lu performed study design. Zhu Zhu, Bingxuan Hua, Zhanxian Shang, Gongsheng Yuan, Lirong $\mathrm{Xu}$, and Ermin Li conducted the study. Zhu Zhu, Bingxuan Hua, Zhanxian Shang, Gongsheng Yuan, and Lirong Xu conducted data collection. Zhu Zhu, Bingxuan Hua, and Zhanxian Shang conducted data analysis.
Zhu Zhu, Bingxuan Hua, Xiaobo Li, Ning Sun, Zuoqin Yan, Ruizhe Qian, and Chao Lu conducted data interpretation. Zhu Zhu, Bingxuan Hua, Ruizhe Qian, and Chao Lu drafted the paper. All authors approved the final version of the paper. Chao $\mathrm{Lu}$ takes responsibility for the integrity of the data analysis.

\section{Acknowledgments}

The authors thank Dr. Jianfa Zhang for generously providing single cosinor method that was used for analysis of circadian rhythm. This work was supported by the National Natural Science Foundation of China (NSFC 81570771) and the National Science Foundation Fostering Talents in Basic Research of China (no. J1210041).

\section{References}

[1] M. R. Ralph, R. G. Foster, F. C. Davis, and M. Menaker, "Transplanted suprachiasmatic nucleus determines circadian period," Science, vol. 247, no. 4945, pp. 975-978, 1990.

[2] J. Bass and J. S. Takahashi, "Circadian integration of metabolism and energetics," Science, vol. 330, no. 6009, pp. 1349-1354, 2010.

[3] U. Schibler, J. Ripperger, and S. A. Brown, "Peripheral circadian oscillators in mammals: time and food," Journal of Biological Rhythms, vol. 18, no. 3, pp. 250-260, 2003.

[4] J. Mendoza, P. Pévet, and E. Challet, "High-fat feeding alters the clock synchronization to light," Journal of Physiology, vol. 586, no. 24, pp. 5901-5910, 2008.

[5] K.-F. Storch, O. Lipan, I. Leykin et al., "Extensive and divergent circadian gene expression in liver and heart," Nature, vol. 417, no. 6884 , pp. $78-83,2002$.

[6] D. M. Flavell, Y. Jamshidi, E. Hawe et al., "Peroxisome proliferator-activated receptor $\alpha$ gene variants influence progression of coronary atherosclerosis and risk of coronary artery disease," Circulation, vol. 105, no. 12, pp. 1440-1445, 2002.

[7] O. Froy, "Metabolism and circadian rhythms-implications for obesity," Endocrine Reviews, vol. 31, no. 1, pp. 1-24, 2010.

[8] S. Takahashi, I. Inoue, Y. Nakajima et al., "A promoter in the novel exon of hPPAR $\gamma$ directs the circadian expression of PPAR $\gamma$," Journal of Atherosclerosis and Thrombosis, vol. 17, no. 1, pp. 73-83, 2010.

[9] S. W. Beaven and P. Tontonoz, "Nuclear receptors in lipid metabolism: targeting the heart of dyslipidemia," Annual Review of Medicine, vol. 57, pp. 313-329, 2006.

[10] D. Mozaffarian, E. J. Benjamin, A. S. Go et al., "Heart disease and stroke statistics-2015 update: a report from the American Heart Association," Circulation, vol. 131, no. 4, pp. e29-e322, 2015.

[11] C. M. Shay, H. Ning, S. R. Daniels, C. R. Rooks, S. S. Gidding, and D. M. Lloyd-Jones, "Status of cardiovascular health in US adolescents: prevalence estimates from the National Health and Nutrition Examination Surveys (NHANES) 2005-2010," Circulation, vol. 127, no. 13, pp. 1369-1376, 2013.

[12] M. R. F. Linton, P. G. Yancey, S. S. Davies et al., "The role of lipids and lipoproteins in atherosclerosis," in Endotext, L. J. De Groot, P. Beck-Peccoz, G. Chrousos et al., Eds., MDText.com, South Dartmouth, Mass, USA, 2000.

[13] J.-P. Despres, S. Lemieux, B. Lamarche et al., "The insulin resistance dyslipidemic syndrome: contribution of visceral obesity and therapeutic implications," International Journal of Obesity, vol. 19, supplement 1, pp. S76-S86, 1995. 
[14] C. S. Fox, J. M. Massaro, U. Hoffmann et al., "Abdominal visceral and subcutaneous adipose tissue compartments: association with metabolic risk factors in the framingham heart study," Circulation, vol. 116, no. 1, pp. 39-48, 2007.

[15] C. B. Anea, M. Zhang, D. W. Stepp et al., "Vascular disease in mice with a dysfunctional circadian clock," Circulation, vol. 119, no. 11, pp. 1510-1517, 2009.

[16] M. Ha and J. Park, "Shiftwork and metabolic risk factors of cardiovascular disease," Journal of Occupational Health, vol. 47, no. 2, pp. 89-95, 2005.

[17] T. Mohri, N. Emoto, H. Nonaka et al., "Alterations of circadian expressions of clock genes in Dahl salt-sensitive rats fed a highsalt diet," Hypertension, vol. 42, no. 2, pp. 189-194, 2003.

[18] J. Xu, W. Yang, Q. Deng, Q. Huang, J. Yang, and F. Huang, "Flaxseed oil and $\alpha$-lipoic acid combination reduces atherosclerosis risk factors in rats fed a high-fat diet," Lipids in Health and Disease, vol. 11, article 148, 2012.

[19] S. Puttonen, M. Kivimäki, M. Elovainio et al., "Shift work in young adults and carotid artery intima-media thickness: the cardiovascular risk in young Finns study," Atherosclerosis, vol. 205, no. 2, pp. 608-613, 2009.

[20] S.-I. Imai, C. M. Armstrong, M. Kaeberlein, and L. Guarente, "Transcriptional silencing and longevity protein Sir2 is an NAD-dependent histone deacetylase," Nature, vol. 403, no. 6771, pp. 795-800, 2000.

[21] Y. Nakahata, M. Kaluzova, B. Grimaldi et al., "The NAD+dependent deacetylase SIRT1 modulates clock-mediated chromatin remodeling and circadian control," Cell, vol. 134, no. 2, pp. 329-340, 2008.

[22] S. Stein and C. M. Matter, "Protective roles of SIRT1 in atherosclerosis," Cell Cycle, vol. 10, no. 4, pp. 640-647, 2011.

[23] J. A. Baur, K. J. Pearson, N. L. Price et al., "Resveratrol improves health and survival of mice on a high-calorie diet," Nature, vol. 444, no. 7117, pp. 337-342, 2006.

[24] M. Lagouge, C. Argmann, Z. Gerhart-Hines et al., "Resveratrol improves mitochondrial function and protects against metabolic disease by activating SIRT1 and PGC-1 $\alpha$," Cell, vol. 127, no. 6, pp. 1109-1122, 2006.

[25] J. N. Feige, M. Lagouge, C. Canto et al., "Specific SIRT1 activation mimics low energy levels and protects against dietinduced metabolic disorders by enhancing fat oxidation," Cell Metabolism, vol. 8, no. 5, pp. 347-358, 2008.

[26] F. Picard, M. Kurtev, N. Chung et al., "Sirtl promotes fat mobilization in white adipocytes by repressing PPAR- $\gamma$," Nature, vol. 429, no. 6993, pp. 771-776, 2004.

[27] C. Xu, C. Lu, L. Hua et al., "Rhythm changes of clock genes, apoptosis-related genes and atherosclerosis-related genes in apolipoprotein E knockout mice," Canadian Journal of Cardiology, vol. 25, no. 8, pp. 473-479, 2009.

[28] S. H. Zhang, R. L. Reddick, J. A. Piedrahita, and N. Maeda, "Spontaneous hypercholesterolemia and arterial lesions in mice lacking apolipoprotein E," Science, vol. 258, no. 5081, pp. 468471, 1992.

[29] A. S. Plump, J. D. Smith, T. Hayek et al., "Severe hypercholesterolemia and atherosclerosis in apolipoprotein E-deficient mice created by homologous recombination in ES cells," Cell, vol. 71, no. 2, pp. 343-353, 1992.

[30] L. Hou, C. Lu, Y. Huang, S. Chen, L. Hua, and R. Qian, "Effect of hyperlipidemia on the expression of circadian genes in apolipoprotein E knock-out atherosclerotic mice," Lipids in Health and Disease, vol. 8, article no. 60, 2009.
[31] W. Nelson, Y. L. Tong, J. K. Lee, and F. Halberg, "Methods for cosinor-rhythmometry," Chronobiologia, vol. 6, no. 4, pp. 305323, 1979.

[32] H. Esterbauer, G. Wag, and H. Puhl, "Lipid peroxidation and its role in atherosclerosis," British Medical Bulletin, vol. 49, no. 3, pp. 566-576, 1993.

[33] B. W. McCrindle, E. M. Urbina, B. A. Dennison et al., "Drug therapy of high-risk lipid abnormalities in children and adolescents: a scientific statement from the American Heart Association atherosclerosis, hypertension, and obesity in youth committee, council of cardiovascular disease in the young, with the council on cardiovascular nursing," Circulation, vol. 115, no. 14, pp. 1948-1967, 2007.

[34] N. Preitner, F. Damiola, Luis-Lopez-Molina et al., "The orphan nuclear receptor REV-ERB $\alpha$ controls circadian transcription within the positive limb of the mammalian circadian oscillator," Cell, vol. 110, no. 2, pp. 251-260, 2002.

[35] I. Lemieux, L. Laperrière, V. Dzavik, G. Tremblay, J. Bourgeois, and J.-P. Després, "A 16-week fenofibrate treatment increases LDL particle size in type IIA dyslipidemic patients," Atherosclerosis, vol. 162, no. 2, pp. 363-371, 2002.

[36] W. Verreth, D. De Keyzer, M. Pelat et al., "Weight loss-associated induction of peroxisome proliferator-activated receptor- $\alpha$ and peroxisome proliferator-activated receptor- $\gamma$ correlate with reduced atherosclerosis and improved cardiovascular function in obese insulin-resistant mice," Circulation, vol. 110, no. 20, pp. 3259-3269, 2004.

[37] M. Sasaki, P. Jordan, T. Welbourne et al., "Troglitazone, a PPAR- $\gamma$ activator prevents endothelial cell adhesion molecule expression and lymphocyte adhesion mediated by TNF- $\alpha$," BMC Physiology, vol. 5, no. 1, article 3, 2005.

[38] K. De Bosscher, W. Vanden Berghe, and G. Haegeman, "Crosstalk between nuclear receptors and nuclear factor $\kappa \mathrm{B}$," Oncogene, vol. 25, no. 51, pp. 6868-6886, 2006.

[39] S. Kadiri, C. Monnier, M. Ganbold, T. Ledent, J. Capeau, and B. Antoine, "The nuclear retinoid-related orphan receptor$\alpha$ regulates adipose tissue glyceroneogenesis in addition to hepatic gluconeogenesis," American Journal of PhysiologyEndocrinology and Metabolism, vol. 309, no. 2, pp. E105-E114, 2015.

[40] P. Delerive, D. Monté, G. Dubois et al., "The orphan nuclear receptor $\mathrm{ROR} \alpha$ is a negative regulator of the inflammatory response," EMBO Reports, vol. 2, no. 1, pp. 42-48, 2001.

[41] E. Vieira, E. G. Ruano, A. L. C. Figueroa et al., "Altered clock gene expression in obese visceral adipose tissue is associated with metabolic syndrome," PLoS ONE, vol. 9, no. 11, Article ID el11678, 2014.

[42] M. Aoki, T. Nata, R. Morishita et al., "Endothelial apoptosis induced by oxidative stress through activation of NF- $\kappa \mathrm{B}$ : antiapoptotic effect of antioxidant agents on endothelial cells," Hypertension, vol. 38, no. 1, pp. 48-55, 2001.

[43] L. Lin, F. Peng, Y. Liu et al., "Coadministration of VDR and RXR agonists synergistically alleviates atherosclerosis through inhibition of oxidative stress: An In Vivo and In Vitro Study," Atherosclerosis, vol. 251, pp. 273-281, 2016.

[44] L. K. Fonken, J. L. Workman, J. C. Walton et al., "Light at night increases body mass by shifting the time of food intake," Proceedings of the National Academy of Sciences of the United States of America, vol. 107, no. 43, pp. 18664-18669, 2010.

[45] C. Dibner, U. Schibler, and U. Albrecht, "The mammalian circadian timing system: organization and coordination of central and peripheral clocks," Annual Review of Physiology, vol. 72, pp. 517-549, 2009. 

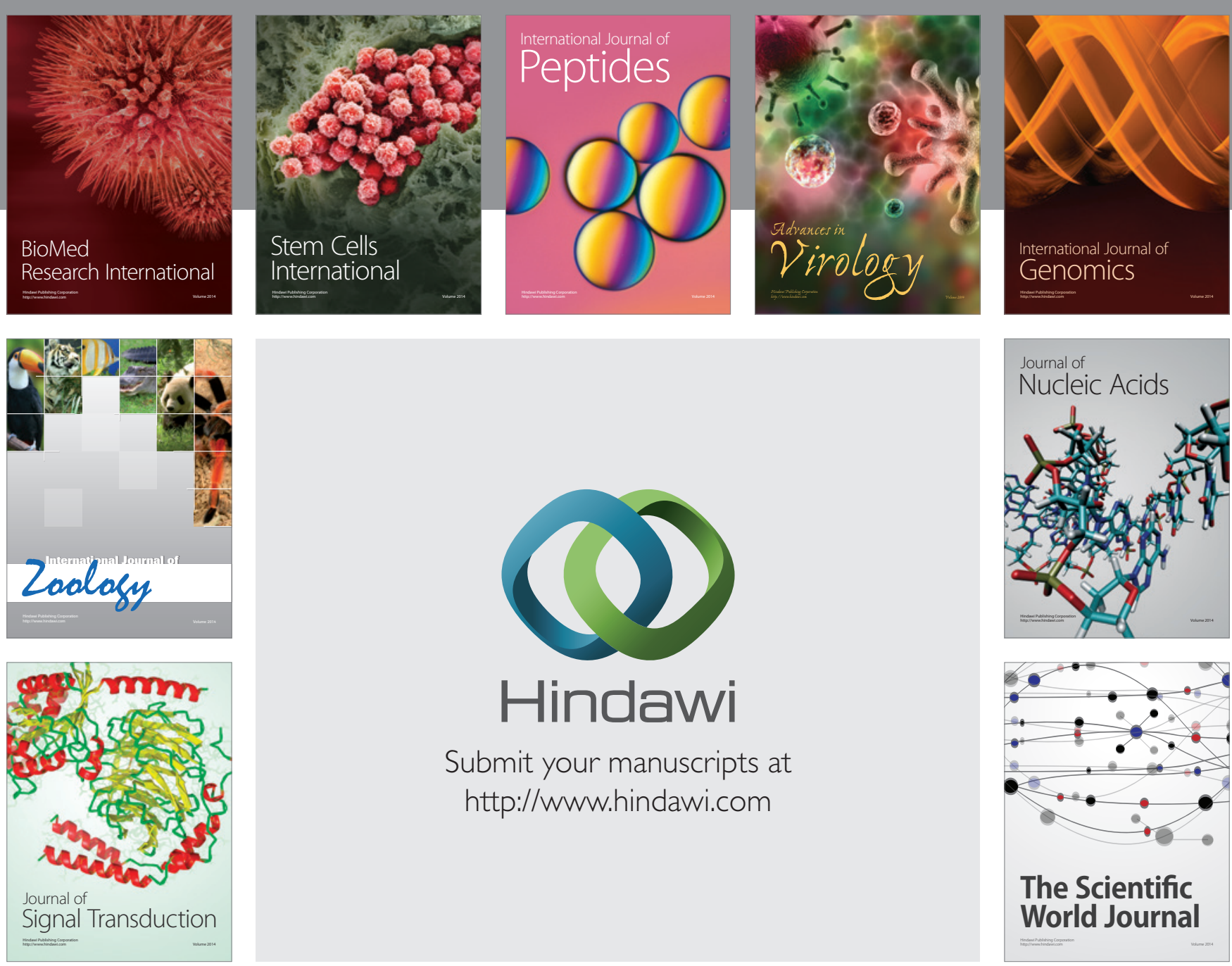

Submit your manuscripts at

http://www.hindawi.com
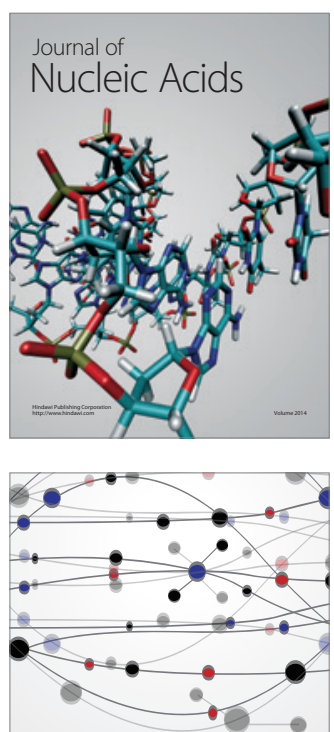

The Scientific World Journal
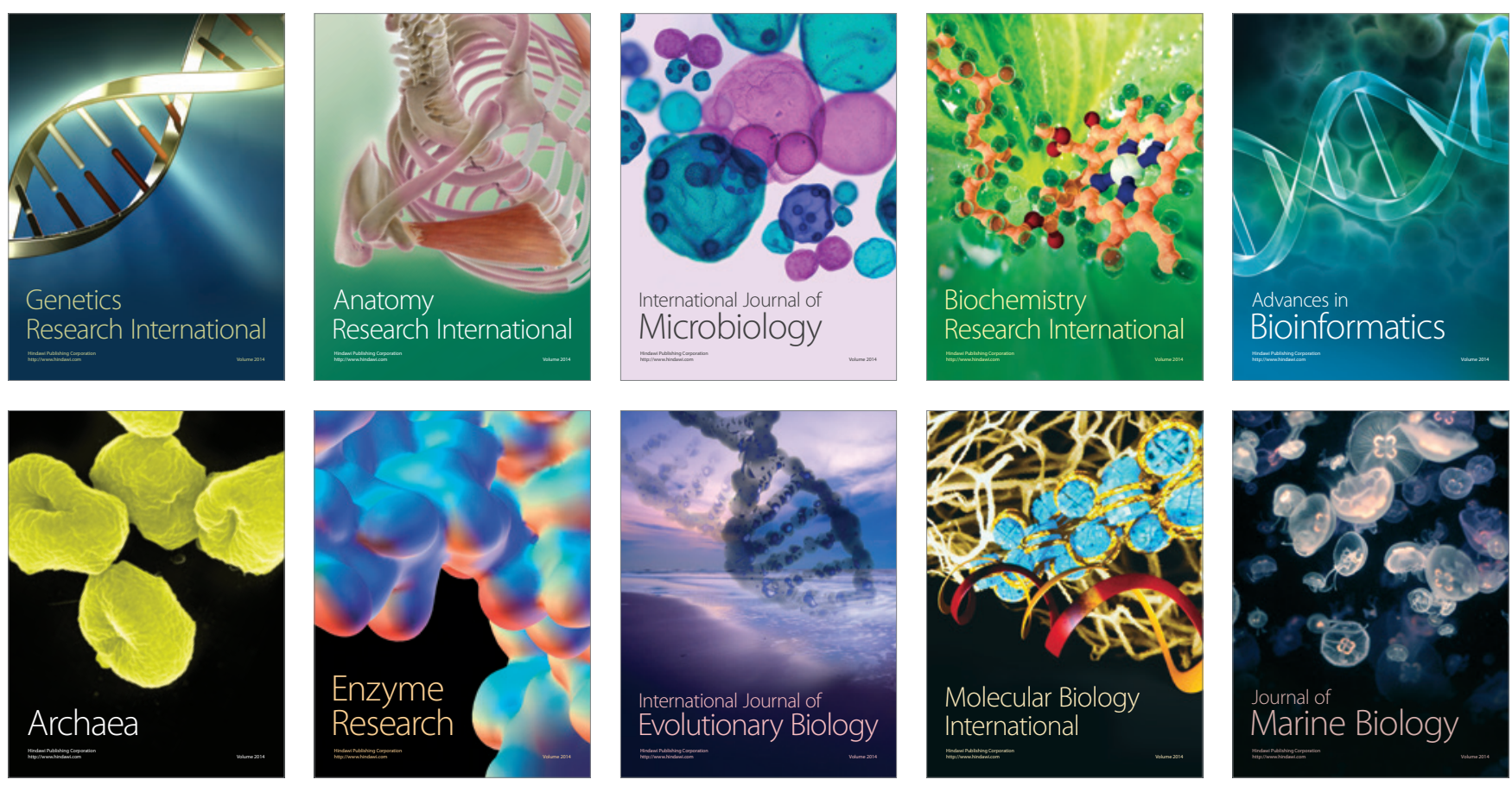